\title{
EL PRINCIPIO DE ACCESO UNIVERSAL Y LA REGULACIÓN DE BANDA ANCHA*
}

\author{
Lucas Sierra
}

\begin{abstract}
Este trabajo intenta pensar el principio del acceso universal, un principio regulatorio clásico de las telecomunicaciones, en relación con la banda ancha (BA). El acceso universal es un principio de igualdad que, al mismo tiempo, está asociado a la economía de las redes de telecomunicaciones. El contenido igualitario del acceso universal, se sostiene aquí, adquiere renovada fuerza frente a la BA por el acceso inédito que ésta franquea al conocimiento. A partir de estas premisas, el trabajo repasa históricamente nuestra regulación de telecomunicaciones, distinguiendo las distintas caras que este principio ha mostrado: subsidios, la noción de "servicio público", las obligaciones de interconexión y, en algún sentido, la discusión sobre una
\end{abstract}

LuCAS Sierra. Abogado, Universidad de Chile. Master en derecho (LL. M) Yale University. Doctor (Ph. D.) Cambridge University. Profesor de derecho de las telecomunicaciones en la Universidad de Chile. Investigador del CEP.

* Agradezco el buen trabajo de Pablo Fuenzalida como ayudante de investigación. También los datos provistos por Raúl Arrieta sobre el Fondo de Desarrollo de las Telecomunicaciones (FDT), y una interesante conversación con Harald Beyer, Daniel Bonacic, José Molés y Humberto Soto. Ninguna de estas personas, sobra decirlo, tiene responsabilidad alguna en los errores y omisiones que pueden haber quedado. Este trabajo es parte de un proyecto de investigación sobre la regulación de las telecomunicaciones en Chile, que la Fundación País Digital me ha encargado. Su contenido y conclusiones son de mi exclusiva responsabilidad y no reflejan necesariamente el punto de vista de esa fundación. 
eventual obligación de desagregar redes. El trabajo sugiere que el acceso universal en Chile está bastante honrado por la telefonía, en especial la móvil. Pero afirma también que respecto de la BA todavía falta camino por andar. Para recorrerlo, sugiere persistir con el mecanismo de subsidios y con las obligaciones de interconexión, y sugiere, además, discutir de buena fe la posibilidad de desagregación. Es enfático, sin embargo, en rechazar la noción de "servicio público" para la BA y sus aplicaciones. Esto, por la pesada carga regulatoria que dicha noción envuelve.

El día después de la Navidad de 1933 a Armstrong se le otorgaron cuatro patentes por su invención más significativa: la radio FM. Hasta entonces, la radio comercial había sido de amplitud modulada (AM).

Los teóricos de esa época habían dicho que una radio de frecuencia modulada jamás podría funcionar. Tenían razón por lo que respecta a una radio FM en una banda estrecha del espectro. Pero

Armstrong descubrió que una radio de frecuencia modulada en una banda ancha del espectro podría proporcionar una calidad de sonido asombrosamente

fiel, con mucho menos consumo del transmisor y menos estática.

(Lawrence Lessig, Cultura Libre)

\section{Introducción}

E

ste trabajo tiene que ver con un principio que está presente desde hace tiempo en la regulación de las telecomunicaciones: el "acceso universal”. Significa que las telecomunicaciones deben ser accesibles a todas las personas, como regla general. Está presente en la regulación chilena de las telecomunicaciones desde muy antiguo. Tuvo que ver con la telegrafía, luego con la telefonía y, en algún sentido, también con la radiodifusión. Este trabajo lo intenta pensar en relación con la banda ancha (BA).

Usualmente hablando, BA se refiere a circuitos y señales de alta velocidad, a una cierta velocidad para procesar datos digitales. Esta velocidad es medida en bps (bit per second). ¿A partir de qué velocidad se puede hablar de BA? No hay una respuesta unánime a esta pregunta. Para algunos, de los $128 \mathrm{kbps}$ para arriba, para otros desde los $256 \mathrm{kbps}$, para otros desde los 600 kbps, desde 1 Mbps y así sucesivamente. 
En Chile, el Tribunal de Defensa de la Libre Competencia definió en 2004 el mercado de la BA así:

[...] aquel que asegura al usuario una conexión permanente a Internet a una velocidad de 128 Kbps o superior, tanto de subida como de bajada. Actualmente se puede acceder al servicio de banda ancha principalmente a través de tres tecnologías: xDSL, cable MODEM y WLL. En etapa experimental se encuentran el acceso a banda ancha por medio de líneas de energía (PLC), acceso por satélite y fibra óptica al hogar (FTTH) ${ }^{1}$.

La International Telecommunication Union (ITU) es un poco más ambiciosa que nuestro tribunal antimonopolios, pues comienza a hablar de BA a partir de los 256 kbps:

En general, se considera que la banda ancha corresponde a una velocidad de transmisión igual o superior a $256 \mathrm{kbit} / \mathrm{s}$, e incluso algunos operadores denominan la velocidad básica RDSI (144 kbit/s) como un "tipo de banda ancha". En este Informe, aunque no se define específicamente la banda ancha, se considera que en general $256 \mathrm{kbit} / \mathrm{s}$ es la velocidad mínima ${ }^{2}$.

${ }^{1}$ En la consulta por la fusión VTR-Metrópolis en http://www.tdlc.cl/db_images/ resoluciones/42d6afeed6a87_Resolucion-1-2004.pdf.

${ }^{2}$ En http://www.itu.int/osg/spu/publications/sales/birthofbroadband/ExecSumm_es. pdf. La ITU establece un piso más alto para BA a través de redes tecnológicas más específicas, fuera de los mercados masivos de BA, como las "redes digitales de servicios integrados" (RDSI). Para hablar de BA exige una velocidad "primaria” de 1,5 ó 2,0 Mbps. En http://www.itu.int/osg/spu/publications/birthofbroadband/faq-en.html.

En Chile, la preocupación por definir un piso mínimo para hablar de BA llevó a los diputados Gonzalo Uriarte y Gonzalo Arenas (ambos UDI) a redactar un proyecto de ley que modifica la legislación que protege al consumidor en los siguientes términos: “Agréguese un nuevo artículo 33 A, a la ley 19.496 sobre protección del consumidor, del siguiente tenor: Artículo 33.- En los servicios de conexión a Internet, se entenderá por 'Banda Ancha' el uso de redes que tienen la facultad de establecer comunicaciones bidireccionales a muy alta velocidad, las cuales permitan poder transmitir video, audio y datos prácticamente en tiempo real. En todo caso, las velocidades entregadas por los proveedores como servicios de 'Banda Ancha', no podrán ser inferiores al límite menor establecido por la Unión Internacional de Telecomunicaciones (UIT) para dicho tipo de conexiones”. Disponible en http://sil.congreso.cl/docsil/proy4919.doc. No parece ser ésta una buena idea, pues el piso para la BA va a seguir evolucionando de la forma impredecible con que evoluciona la tecnología. No debería rigidizarse por ley. Si de lo que se trata es de prohibir la publicidad engañosa, es mejor confiar en el sistema general de protección del consumidor que ya existe. 
En esto se parece a lo señalado por el regulador de las telecomunicaciones en Estados Unidos, la Federal Communication Commission (FCC), para quien la BA requiere una velocidad mínima de 200 kbps en uno de los dos sentidos de la comunicación, ascendente (upstream, del usuario al proveedor) o descendente (downstream, del proveedor al usuario). Para la OECD, la BA parte de los 256 kbps en un sentido descendente ${ }^{3}$. La mayor cantidad de opiniones parece converger en una velocidad mínima de 256 kbps de bajada para empezar a hablar de BA.

Cualquiera sea la velocidad que en definitiva acordemos, es pertinente pensar la BA en relación con el principio regulatorio de acceso universal. Este principio está atravesado por una lógica igualitaria: es un principio de igualdad. La BA puede satisfacer este requerimiento de igualdad de una forma muy interesante, por el enorme acceso que franquea al conocimiento mediante Internet. Es una ventana amplísima a las cosas del mundo, ventana a la que la mayor cantidad de ciudadanos debería tener la posibilidad de asomarse. ¿Qué debería hacer la regulación para permitir que esto sea así?

Este trabajo intenta contestar esa pregunta a través del siguiente itinerario. Primero (1) revisa la historia del principio de acceso universal en la regulación chilena de las telecomunicaciones. Detecta en esta historia varias caras que el principio ha asumido: subsidios, obligaciones de "servicio público”, obligación de interconexión, incluida, además, la discusión sobre la posibilidad de desagregar redes. Luego (2) estudia la regulación vigente y el modo en que en ella aparecen estas distintas caras. Se detiene algo más en el mecanismo de subsidios, apuntando algunos datos sobre el Fondo de Desarrollo de las Telecomunicaciones. Después (3) sugiere la idea de que el principio de acceso universal en Chile está bastante honrado por la telefonía, en especial la celular. Acto seguido (4) se pregunta por la situación de la BA a estos respectos, identificando ciertos subsidios especiales que ésta tiene. Luego (5) avanza criterios para una regulación que satisfaga el principio de acceso universal en relación con la BA. Se sugiere desechar la idea de "servicio público" para la BA y sus aplicaciones, pues el "servicio público" conlleva una mano regulatoria excesivamente pesada, en circunstancias que la BA necesita la menor regulación que sea posible. Se sugiere utilizar, en cambio, algún mecanismo de subsidio, mantener la obligación de interconexión, cuidar el espectro radioeléctrico y pensar alguna posibilidad de desagregación. Se concluye en (6).

${ }^{3}$ Para la FCC, ver http://www.fcc.gov/cgb/consumerfacts/highspeedinternet.html. Para la OECD ver http://www.oecd.org/document/7/0,3343,en_2649_34223_38446855 _1_1_1_1,00.html. 


\section{El acceso universal en la historia}

El principio de acceso universal tiene un contenido normativo asociado a una relativa igualdad de las personas frente a la posibilidad de emitir y recibir contenido simbólico mediante los medios de telecomunicación. Distintas definiciones se han ensayado de este concepto, pero en todas subyace una cierta idea de igualdad en relación con las telecomunicaciones. Por ejemplo, la International Telecommunication Union (ITU) ha definido el acceso universal a las telecomunicaciones "[...] como parte del derecho a comunicarse, y a la necesidad de que la reglamentación asegure la disponibilidad geográfica universal, la igualdad de trato mediante un acceso no discriminatorio y un costo accesible”. Por su parte, la Unión Europea ha entendido: "la obligación impuesta a uno o más operadores de redes y/o de servicios de comunicaciones electrónicas de suministrar, a un precio razonable, un conjunto mínimo de servicios a todos los usuarios, independientemente de su situación geográfica en el territorio nacional”4 . Así, con este carácter normativo asociado a la igualdad, está recogido en la legislación chilena de las telecomunicaciones vigente, como se verá más abajo.

Pero el principio de acceso universal también contiene elementos de un carácter más descriptivo, asociado a una característica de las telecomunicaciones entendidas como redes, característica que, precisamente, se llama "externalidades de red". Al respecto, Neuchterlein y Weiser (2005: 352) han escrito: "Las políticas sobre 'servicio universal', en el sentido más restringido del término, son defendidas por ser necesarias para facilitar las externalidades de red - esto es, el aumento del valor de la red para cada usuario debido al aumento en el número de otros usuarios de la misma"5. En otras palabras, mayor es el valor de una red de telecomunicaciones para un usuario, mientras más sean los demás usuarios de la misma.

A fin de facilitar la producción de estas externalidades de red, desde el siglo XIX se viene intentado el despliegue de redes de telecomunicaciones. Durante el siglo XIX, este intento tomó la forma de subsidios a proyectos de inversión que tendieran y operaran redes de telegrafía y, luego, de telefonía. En el siglo XX ese intento de desplegar redes se vio, además, adornado con un discurso en pro de una cierta igualdad de los ciudadanos frente a las telecomunicaciones. Se empieza a hacer una referencia al acceso

${ }^{4}$ La definición de la ITU es de 1998 y está en http://www.itu.int/ITU-D/ study_groups/SGP_1998-2002/SG1/Documents/1998/008-es.pdf. La de la Unión Europea es de 2002 y está en http://europa.eu/scadplus/leg/es/lvb/l24108h.htm.

${ }^{5}$ Neuchterlein y Weiser (2005: 352). Traducción propia. 
universal como principio y, además de los subsidios, se comienzan a ensayar otros mecanismos para materializarlo, como la noción de "servicio público", la obligación de interconexión y, de alguna manera, la obligación de desagregación. Veámoslos en orden.

\subsection{Subsidios}

Este mecanismo consistió en apoyo financiero directo y en la liberación de derechos de importación. Un ejemplo de lo primero fue la "Ley sobre subvención concedida a los señores Clark \& Cía., empresarios de un telégrafo eléctrico entre Valparaíso, Santiago i Buenos Aires”, en 1871. Un ejemplo de lo segundo fue la "Ley que libera de derechos de internación de materiales i aparatos para su construcción respecto a la línea telegráfica de Caldera a Lota”, dictada en 1873, en beneficio de Enrique López Vargas, a quien se le permitió, además, instalar en terrenos fiscales los postes de su línea. Otro ejemplo es de 1889: la "Ley que declara la liberación de derechos de internación de los objetos que se indican", entre los que se contaban aparatos telefónicos, aisladores, postes, etc. Y otro, la "Ley que dispensa el pago de diez mil pesos de derechos de internación a la Sociedad Nacional de Teléfonos”, de 1890. Este subsidio a la instalación y operación de redes de telecomunicaciones existe hoy en día, y lo provee el Fondo de Desarrollo de las Telecomunicaciones (FDT). Obviamente, la fisonomía del subsidio provisto por este fondo es distinta a la de los subsidios de esas leyes del siglo XIX. Pero todos comparten la misma lógica: incentivar el despliegue de redes de telecomunicaciones.

\section{2. "Servicio público"}

El principio de acceso universal también ha estado asociado con una idea regulativa propia del derecho administrativo: el "servicio público". Aquí la lógica cambia desde el incentivo al despliegue de redes hasta la obligación de dar servicio a todos los potenciales usuarios dentro del área de concesión. En 1931, con Ibáñez en el poder, se dictó el Decreto con Fuerza de Ley 244, Ley General de Servicios Eléctricos, primera norma legislativa que así lo dispuso. Decía: "Los concesionarios de servicio público están obligados a dar servicio a los que lo soliciten en conformidad a los reglamentos, en las zonas que el Presidente de la República declare obligatorias y que estén comprendidas dentro el territorio de la concesión, siem- 
pre que estos consumos sean compatibles con la capacidad y seguridad de sus instalaciones. La contravención a este artículo será penada con multa en la forma que dispongan los reglamentos". Esta idea de "servicio público" sigue presente en nuestra regulación hoy. Por ejemplo, la telefonía fija y móvil se califican como "servicio público de telecomunicaciones".

\subsection{Interconexión}

Con los años, el principio de acceso universal adoptó una nueva cara: la interconexión. No se trató de un subsidio al despliegue de redes, ni tampoco de la obligación para estas redes de servir a todos los interesados que se encuentran en su área de concesión, pero sí de la obligación de las redes existentes de conectarse unas con otras. La primera norma legislativa que estableció esta obligación fue el Decreto con Fuerza de Ley 4, Ley General de Servicios Eléctricos: "Los concesionarios están obligados a llevar a cabo la interconexión de sus instalaciones cuando el Presidente de la República, con informe de la Dirección, la considere conveniente para la mejor explotación de sus respectivas concesiones o de cualquiera de ellas. En caso de falta de acuerdo entre los concesionarios sobre la forma de realizar la interconexión y de efectuar el transporte o transferencia de la energía o sobre la forma de realizar las telecomunicaciones combinadas, la Dirección oirá a los concesionarios y resolverá al respecto. En ningún caso la interconexión podrá significar gastos perjudiciales para los concesionarios”. La obligación de interconectarse sigue vigente en nuestra regulación.

\subsection{Desagregación}

En estos días, en fin, el principio de acceso universal parecería tener otra nueva cara: la desagregación de redes. Esta obligación de desagregar parece ser un paso más allá de la obligación de interconectarse. En esta última, la comunicación desde un usuario de una red hacia el usuario de otra es entregada por la red del primero a la red del segundo, para que sea ésta la que complete la comunicación. En el caso de la desagregación, en cambio, es la propia red del primer usuario la que se conecta con el segundo, completando ella misma la comunicación a través de la red de este segundo. Esta segunda red no interviene más que en esto, sólo se abre hasta su cliente. Podrá cobrar un precio por este paso, pero no puede negarlo. Éste es el núcleo de la obligación de desagregar redes: abrir el paso 
hasta el usuario final. Después se podrá negociar por cuánto, pero el paso ya está abierto ${ }^{6}$.

A raíz de una consulta pública que el gobierno realizó el año 2004, con ideas para dictar un reglamento, se discutió con alguna intensidad sobre desagregación. Luego el debate decayó y el gobierno, hasta ahora, no ha vuelto a levantar el punto. Esto debe tener que ver con el problemático carácter que tiene la desagregación, y con la disparidad de opiniones que hay sobre su conveniencia. Más abajo se volverá sobre esto. Antes, un repaso al modo en que la regulación vigente concibe el principio de acceso universal y sus distintas caras.

\section{El principio de acceso universal y la regulación vigente}

La legislación vigente, la Ley 18.168, es la que, históricamente, se ha referido con más enjundia a este principio. Dice: “Todos los habitantes de la República tendrán libre e igualitario acceso a las telecomunicaciones y cualquier persona podrá optar a las concesiones y permisos que establece la ley, salvo en los casos de excepción que las leyes expresamente señalen”. Esta idea fue reforzada con una reforma en 1994, la Ley 19.277, al extenderla expresamente al espectro radioeléctrico: "Para todos los efectos de esta ley, el uso y goce de frecuencias del espectro radioeléctrico será de libre e igualitario acceso por medio de concesiones, permisos o licencias de telecomunicaciones, especialmente temporales, otorgadas por el Estado".

Como se ve, la ley trata al acceso universal como un principio regulatorio de igualdad. Pero, bien leído, se trata aquí de una idea de igualdad más formal que sustantiva. La ley exige que el acceso a las telecomunicaciones sea "libre" e "igualitario", es decir, prohíbe al regulador el establecimiento de obstáculos y discriminaciones a la hora de mediar en la relación entre todas las personas y las telecomunicaciones. No se trata, por tanto, de una igualdad sustantiva: la ley no garantiza a todas las personas un acceso efectivo y real a las telecomunicaciones, sino que, cosa distinta, garantiza que la posibilidad de acceso esté libre de obstáculos y discriminaciones regulatorias. Es razonable que así sea, pues, como enseñan la experiencia y el sentido común, no se puede asegurar por ley, en la forma de un derecho entregado a las personas, la satisfacción de necesidades por bienes escasos. ¿Tenemos "derecho" a una conexión a BA? ¿Podríamos pedirle a un

${ }^{6}$ Ésta parece una lógica análoga a las servidumbres impuestas por ley: se imponen, con una indemnización que puede fijarse luego, de común acuerdo o por un juez si no hay acuerdo. 
juez que le ordenara a alguien darnos una conexión, porque tenemos "derecho” a ella? No parece razonable contestar que sí. Por esto es insensato un proyecto de reforma constitucional presentado en octubre de 2006 por los diputados Jorge Insunza y Esteban Valenzuela, que pretende garantizar a todas las personas, como derecho constitucional, "el acceso a la conectividad a las redes digitales de información y comunicación”7.

En nuestro sistema jurídico, entonces, el acceso universal es un principio regulatorio que expresa una garantía de igualdad formal, no sustantiva. Para entenderlo de esta última manera — como igualdad sustantiva— es necesario pasar desde el terreno de los derechos hasta el de los objetivos de política. Es decir, al tiempo que se garantiza jurídicamente la libertad y no discriminación en el acceso a las telecomunicaciones, se puede, políticamente, comprometer esfuerzos para que la mayor cantidad posible de personas tenga un acceso efectivo a BA. Este compromiso político ha sido hecho por el actual gobierno. El programa con que compitió en las elecciones 2005 y 2006 señala: "Implementaremos una política de Servicio Universal de Acceso a la Sociedad de la Información, definiendo un conjunto mínimo de prestaciones de una calidad determinada, que estarán disponibles para todos los usuarios a un precio asequible, independientemente de su situación geográfica. Todos los usuarios finales podrán efectuar y recibir llamadas telefónicas y tener acceso a Internet con una calidad funcional y razonable" .

Este trabajo busca avanzar criterios regulatorios para este objetivo de política. Pero antes de ir a ellos, en lo que inmediatamente sigue se revisan las distintas caras con que el principio de acceso universal se muestra en nuestra legislación.

\subsection{Servicio público}

La Ley 18.168 también recoge e intensifica la idea de "servicio público” como obligación de conectar a todos los interesados en el área de concesión. Dice su Art. 24 B: "Las empresas concesionarias de servicio público telefónico estarán obligadas a dar servicio a los interesados que lo soliciten dentro de su zona de servicio y a los que estando fuera de ella y de la de otro concesionario, costeen las extensiones o refuerzos necesarios para llegar hasta ella”.

${ }^{7}$ En http://sil.congreso.cl/docsil/proy4999.doc.

${ }^{8}$ En http://www.lanacion.cl/prontus_noticias/site/artic/20051018/asocfile/ ASOCFILE120051018162635.pdf. 


\subsection{Interconexión}

Y también recoge e intensifica la necesidad de interconexión entre redes. Así, por ejemplo, obliga a los concesionarios de servicios públicos de telecomunicaciones a "establecer y aceptar interconexiones”, y también obliga a los servicios intermedios de larga distancia a establecerlas y aceptarlas entre sí. Tan imbuida está la legislación de la necesidad de interconectar, que se ha establecido un mecanismo permanente de fijación tarifaria a fin de evaluar pecuniariamente las interconexiones.

\subsection{Subsidios}

Tampoco la legislación vigente se olvida de la forma de acceso universal como subsidio directo, que en Chile viene, según se vio más arriba, desde el siglo XIX. Hoy se establece el Fondo de Desarrollo de las Telecomunicaciones (FDT), creado en 1994 por la Ley 19.302. Su objeto fue crear un fondo para "promover el aumento de la cobertura del servicio público telefónico en áreas rurales y urbanas de bajos ingresos con baja densidad telefónica”. Cada año, la Ley de Presupuestos asigna sus montos. El FDT depende del Ministerio de Transportes y Telecomunicaciones, y lo administra un Consejo de Desarrollo de las Telecomunicaciones, compuesto por los ministros de Transportes y Telecomunicaciones, Economía, Hacienda y Mideplán, y por tres profesionales con experiencia en el área de telecomunicaciones y vinculados a las diversas regiones del país. Éstos son designados por la Presidencia de la República.

El FDT fija anualmente su política de subsidio y llama a concursos públicos de proyectos. Para definir su política de subsidio, la ley exige al Consejo del FDT requerir a las municipalidades información sobre las necesidades de telecomunicaciones que tengan sus respectivas comunas.

Como los subsidios del siglo XIX, el FDT nació como un subsidio a la oferta, a la provisión de servicio telefónico, mediante el despliegue y operación de redes. Algunos años después de su creación, en 2001, se dictó la Ley 19.724 que lo reactivó, pues su plazo original había vencido. Esa ley le puso una duración de 10 años y amplió su objeto más allá de la telefonía, en sintonía con el discurso en boga sobre la "sociedad de la información”. Así, el FDT ya no quedó restringido a la telefonía, sino que se amplió a "promover el aumento de la cobertura de los servicios de telecomunicaciones en áreas rurales y urbanas de bajos ingresos, especialmente respecto de localidades ubicadas en zonas geográficas extremas o aisladas”. 
Se amplió de "servicio público telefónico" a "servicios de telecomunicaciones". La ley especifica cuáles pueden ser los distintos proyectos a subsidiar:

- Teléfonos públicos o centros de llamadas.

- Telecentros comunitarios de información.

- $\quad$ Servicios de Telecomunicaciones de libre recepción o de radiodifusión locales.

- $\quad$ Cualquier otro servicio de telecomunicaciones que beneficie directamente a la comunidad en la cual habrá de operar.

Éstas son las caras que el principio de acceso universal tiene hoy en nuestra legislación. Está ausente la cara asociada a la desagregación de redes, la más compleja de todas. Tarde o temprano, sin embargo, se puede llegar a discutirla seriamente.

Antes de trasladar todo este análisis a la BA, se revisa a continuación la práctica que ha exhibido el Fondo de Desarrollo de las Telecomunicaciones (FDT).

\subsubsection{La práctica del FDT}

Desde su creación en 1994, suelen distinguirse tres etapas en la práctica del FDT. La primera desde 1994 hasta 2000, la segunda desde 2000 hasta 2004 y, por último, la tercera desde 2004 hasta la fecha. Se caracterizan como sigue:

- $\quad$ Etapa I (1994-2000). Los esfuerzos del FDT estuvieron puestos en la telefonía rural en áreas aisladas.

- $\quad$ Etapa II (2000-2004). Se amplía el foco desde la telefonía a la así llamada "sociedad de la información". La tarea principal fue subsidiar la creación de infocentros y telecentros, y a subsidiar la conectividad de escuelas rurales ${ }^{9}$. En esta segunda etapa, entonces, el medio fue cambiado desde la telefonía a Internet; y el horizonte fue educación.

${ }^{9}$ Según datos de la Subtel, “[...] a julio de 2002 se registran 192 iniciativas operando, entre las que se cuentan Infocentros y Telecentros. El mayor porcentaje de Infocentros se encuentra bajo la tutela del FOSIS, representando el $29 \%$ del total de la red nacional, a continuación viene SERCOTEC/MINECON con una participación de un 19\%, y posteriormente INJUV, UFRO y SUBTEL alrededor del 7\% cada uno". En http:// www.subtel.cl/pls/portal30/docs/FOLDER/WSUBTEL_CONTENIDOS_SITIO/SUBTEL/INTERNETENCHILE/INTERNETCHILE/INTERNETCHILE2/S_24_INTERNET_EN_CHILE.PDF. 
- $\quad$ Etapa III (2004 hasta la fecha). El horizonte de la educación se ha seguido ampliando. Hay una mayor coordinación con el programa Enlaces, que busca producir valor agregado por la vía de relacionar conectividad y equipos con educación, calidad para los usuarios y competitividad. A partir de este año 2007, además, se vuelve a llamar a concursos por infraestructura. Un buen ejemplo de esto es el proyecto de conectar vía fibra óptica Coyhaique y Chiloé al continente (Proyecto Fibra Óptica Austral).

Veamos ahora la práctica del FDT desde un punto de vista presupuestario $^{10}$. Su flujo se expone en el Cuadro $\mathrm{N}^{0} 1$, medido en miles de pesos de cada año. Como se puede ver en la columna 1, la Ley de Presupuestos 2007 ha asignado la mayor suma hasta ahora:

CUADRO N $1: \quad$ FLUJO PRESUPUESTARIO FDT (1995-2007)

En miles de \$ de cada año

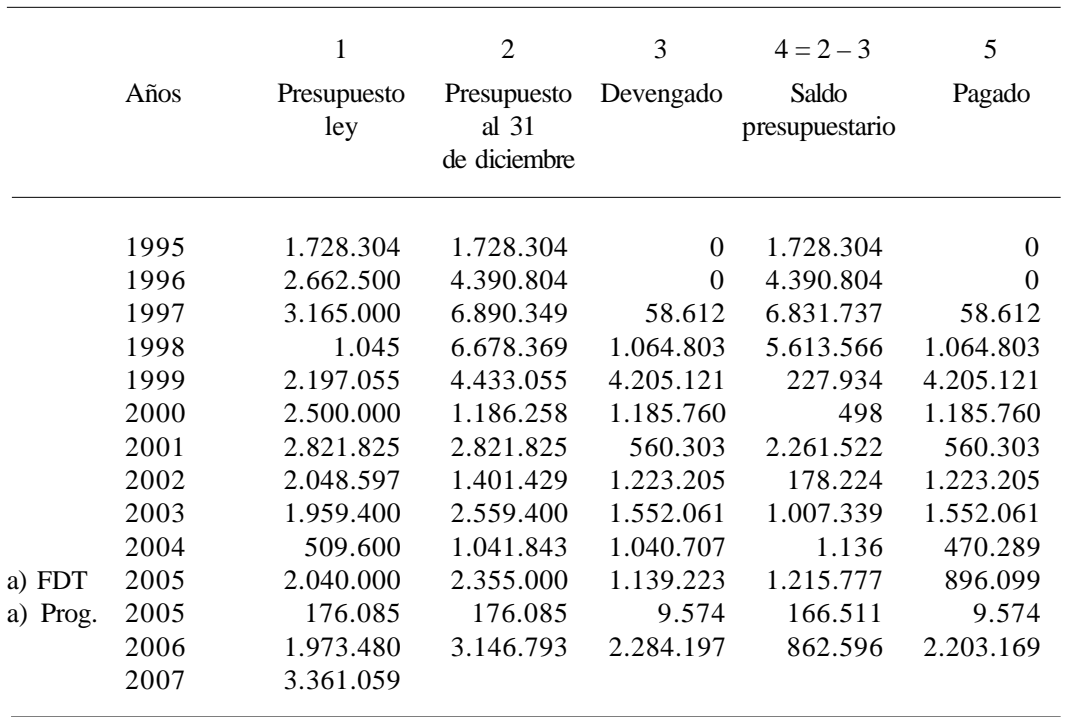

a) El año 2005 la cuenta FDT, según la Ley de Presupuestos, considera presupuesto y gastos del Programa Fortalecimiento de la Estrategia Digital.

Fuente: Subtel (2007).

${ }^{10} \mathrm{Al}$ respecto, en el año 2002 se escribió: "Respecto a los resultados de esta iniciativa [FDT], en cinco años de funcionamiento, se han subsidiado 149 proyectos que han beneficiado a 5.362 localidades, equivalente a 2.002 .982 habitantes, lo que es considerado un éxito a nivel de gobierno debido a la cantidad de localidades identificadas en un 
Uno de los problemas de la práctica del FDT tiene que ver con la sustentabilidad a mediano y largo plazo de los proyectos que subsidia. Ha ocurrido que, al vencerse el plazo de entrega obligatoria del servicio por parte de la empresa subsidiada, algunos teléfonos e instalaciones fueron abandonados. Este problema parece haberse exacerbado en 2001 con la Ley 19.724 sobre el FDT, al prohibirse la participación directa en los concursos de las concesionarias de servicio público de telecomunicaciones, de servicios intermedios que presten servicio telefónico de larga distancia, y de las permisionarias de servicios limitados de televisión, las que sólo pueden hacerlo constituyendo sociedades anónimas que pueden ser filiales suyas. Esta prohibición conllevó un cierto retiro de las grandes empresas, que dejó campo abierto a un conjunto de Pymes (pequeñas y medianas empresas). Muchas de éstas no tuvieron la fortaleza financiera necesaria para mantener los proyectos que les fueron aprobados, y quebraron. Esto ha agravado el problema de sustentabilidad del FDT.

Recientemente, sin embargo, se ha dictado una ley que deroga esa prohibición. Es la Ley 20.196, de julio 2007, que señala: “Podrán presentarse al concurso las personas jurídicas que cumplan con los requisitos legales y reglamentarios para ser titulares de la concesión o permiso del servicio de telecomunicaciones de que se trate, según los casos”. A esta reforma subyace la idea que el FDT tiene por objeto aumentar la conectividad y no fomentar Pymes. Esta idea parece correcta ${ }^{11}$.

comienzo como demanda insatisfecha, la que ascendía a 6.000 localidades. Al 31 de diciembre de 1999 ya se encontraban funcionando 4.423 teléfonos asignados de un total de 5.916 asignados. Hasta esa fecha, los recursos destinados por el Estado a esta iniciativa ascendían a más de nueve mil millones de pesos. Conforme a las estimaciones estatales, con el concurso realizado en 1999 se habría logrado cobertura a un $80 \%$ de las localidades rurales de nuestro país”. Donoso, Lorena: "Servicio Universal de Telecomunicaciones", disponible en http://www.derechoinformatico.uchile.cl/CDA/der_informatico_simple/ 0,1493,SCID\%253D15366\%2526ISID\%253D291\%2526PRT\%253D15360,00.html\#16.

${ }^{11}$ La Ley 20.196 se originó en una moción del senador Jorge Pizarro. En la exposición de motivos de la moción se afirmaba: "la modificación legal del año 2001 en un aspecto introdujo una disfuncionalidad que debe corregirse, toda vez que restringió la participación de las empresas que pueden participar en los concursos para asignar proyectos del Fondo de Desarrollo de las Telecomunicaciones, imponiendo a las concesionarias de servicio público de telecomunicaciones, de servicios intermedios de telecomunicaciones que presten servicio telefónico de larga distancia y las permisionarias de servicio limitado de televisión, la condición de sólo poder hacerlo a través de sociedades anónimas, las que podrán ser filiales de éstas, sujetas a las normas que rigen a las sociedades anónimas abiertas y sometidas a la fiscalización de la Superintendencia de Valores y Seguros, salvo en el caso de los concesionarios de servicios regulados por la ley y los de servicios abiertos o limitados de televisión, que exploten exclusivamente concesiones otorgadas mediante el mecanismo del Fondo de Desarrollo. La experiencia acumulada respecto del alcance y 
Ahora bien, el criterio general de adjudicación usado por el FDT ha sido el menor subsidio por proyecto. Recientemente se está incorporando un criterio tecnológico, que privilegia el uso de fibra óptica por parte del proyecto concursante. Así, el proceso de adjudicación se ha dividido en dos etapas: una primera, en que se preseleccionan proyectos que ofrecen como medio tecnológico la fibra óptica, y una segunda, en que se seleccionan entre ellos los proyectos que requieren un menor subsidio.

Sería interesante un estudio más detallado de la práctica del FDT durante estos 10 años y más de experiencia. Sobre todo ahora que, como se apuntó más arriba, el actual gobierno prometió en su programa una nueva forma para el FDT: "Sustituiremos el actual Fondo de Desarrollo de las Telecomunicaciones por un Fondo de Servicio Universal, que contribuirá al financiamiento de las obligaciones de servicio universal y el desarrollo de proyectos de conectividad”. Este nuevo Fondo estaría vinculado a los siguientes objetivos que el mismo programa enuncia: "Existirán opciones especiales en términos de precio y condiciones de uso, con el objeto de garantizar que las personas con necesidades sociales o con discapacidad puedan tener acceso, al menos, al servicio telefónico. Para aquellos sectores de menores ingresos, zonas rurales y zonas apartadas que no puedan tener acceso a servicios de telecomunicaciones en sus hogares, garantizaremos una oferta suficiente de teléfonos públicos y centros comunitarios de conectividad en todo el territorio nacional que satisfaga razonablemente las necesidades de los usuarios finales" 12 .

¿Cuál es la realidad con que estos altos propósitos se enfrentan hoy?

\section{El acceso universal en telefonía}

La verdad es que se trata de una realidad bastante auspiciosa en términos de acceso universal. Desde la segunda mitad de los años 1990, de la mano de la telefonía móvil (véase Gráfico $\mathrm{N}^{\circ}$ 1), se ha producido un crecimiento sostenido de conectados a la red pública telefónica.

comportamiento de los proyectos del Fondo, permite concluir la necesidad de permitir la participación a estos concursos para todas las empresas que cumplan con los requisitos legales y reglamentarios para ser titulares de la concesión o permiso del servicio de telecomunicaciones de que se trate, según los casos. Limitar la participación de éstas en cualquier forma es limitar las posibilidades de desarrollo del país, ya que se prescinde sin más del aporte que en tal sentido pueden hacer las empresas ya establecidas en este complejo mercado”. Boletín 4521-15.

12 En http://www.lanacion.cl/prontus_noticias/site/artic/20051018/asocfile/ ASOCFILE120051018162635.pdf. 
GRÁFICO No 1: NÚMERO DE ABONADOS MÓVILES Y PENETRACIÓN CADA 100 HABITANTES

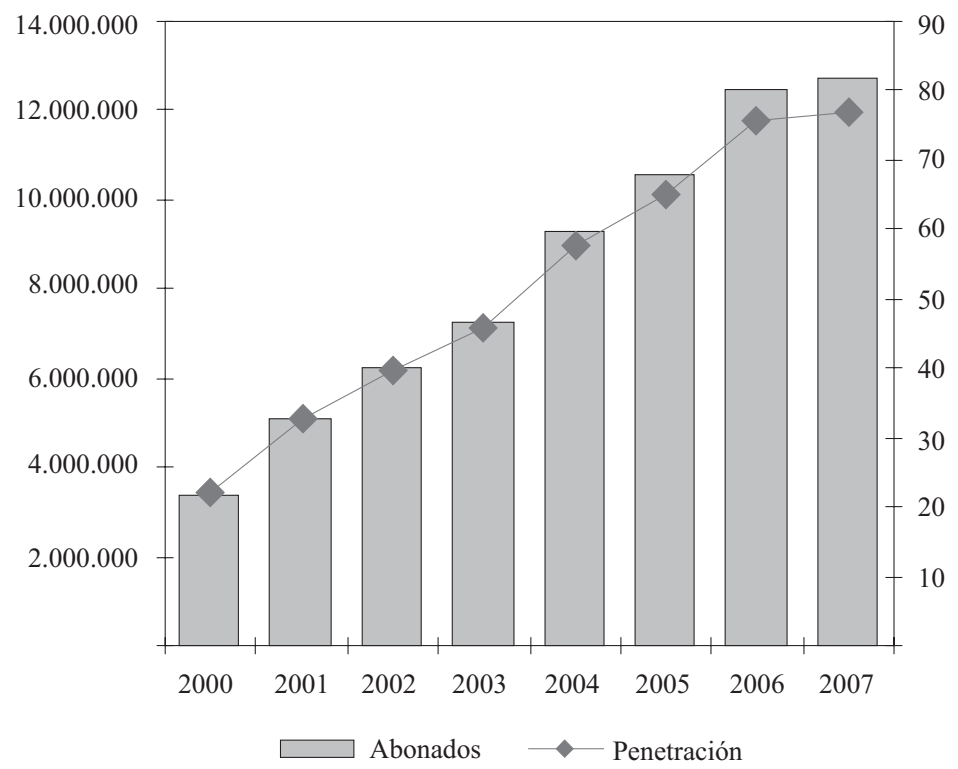

Fuente: Subtel (2007a).

A esto se une, como complemento, la telefonía fija, cuya evolución, según se ve en el Gráfico $N^{\circ} 2$, ha sido más baja, estable e, incluso, regresiva, que la telefonía móvil.

Desde el punto de vista de la telefonía, entonces, pareciera que el principio de acceso universal en Chile está razonablemente satisfecho: nunca ha existido una proporción tan grande de los habitantes del país conectados a la red pública telefónica como la que hoy existe. Esta expansión ha venido fundamentalmente de la mano de la telefonía móvil, la que, dicho sea de paso, no ha recibido subsidios por parte del FDT. La notable cobertura de la telefonía móvil puede apreciarse al descomponerla por niveles de ingreso. La encuesta CEP de junio de 2007 (CEP, 2007), por ejemplo, mostró que en el 78,9 por ciento de los hogares chilenos hay un celular, porcentaje que se divide según niveles de ingreso así: alto, 84 por ciento, medio 84,6 por ciento y bajo 72,5 por ciento ${ }^{13}$.

${ }^{13}$ La telefonía fija carece de esta transversalidad socioeconómica. En un total de 49,7 por ciento de hogares con teléfono fijo, la misma encuesta precisa que los de ingresos altos aportan el 84 por ciento, los de ingresos medios 68,4 por ciento, y los de ingresos bajos sólo 28,2 por ciento. La televisión tiene una transversalidad socioeconómica parecida a la telefonía móvil. La encuesta señala que un total de 93,9 por ciento de los 
GRÁFICO No 2: $\quad$ LÍNEAS DE TELEFONÍA BÁSICA SEGÚN TIPO DE CLIENTE

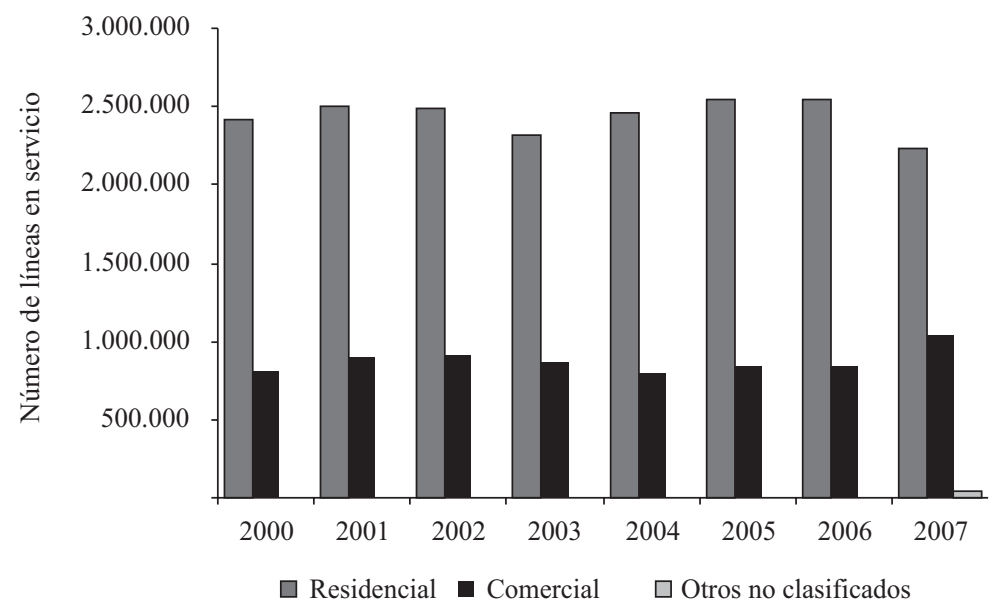

Fuente: Subtel (2007b).

El principio del acceso universal, por tanto, parece gozar de buena salud en Chile gracias a la telefonía. El punto ahora es preguntarse cómo hacerlo para que pase lo mismo respecto de la BA. Como se manifestó al inicio de este trabajo, hay una potente razón de moralidad política —vinculada a la igualdad - para hacerse esta pregunta, pues parece valioso intentar la mayor posibilidad de acceso al conocimiento que circula por BA.

\section{4. ¿Y qué pasa con la BA?}

En relación con la BA, el escenario de la realidad también parece auspicioso. Todavía falta, claro, pero se ha avanzado. Según cifras del Barómetro Cisco de la Banda Ancha (Cisco, 2007), el último trimestre del año 2006, había en el país 1.034.000 conexiones, mientras que en el año 2002 había sólo $186.000^{14}$. Los datos de la Subtel aquí son coincidentes: al primer

hogares tiene TV. Los de ingresos altos en un 88 por ciento, medios en un 95 por ciento y bajos en un 93 por ciento.

${ }^{14}$ El Barómetro Cisco de la Banda Ancha es una iniciativa de la empresa Cisco para promover e incentivar las conexiones de BA en América. En http://www.acti.cl/ actualidad/noticias/barometro_18_01_2007.htm. De acuerdo a este Barómetro, en el cuarto trimestre 2006 se sumaron más de 48.800 conexiones al mercado de BA. Y en el último año, 322.800. Entre diciembre de 2005 y diciembre de 2006, este mercado creció un 45 por ciento, que en parte se explicaría por el crecimiento en los denominados productos Triple Play. Entre 2005 y 2006, el crecimiento de la conectividad en empresas experimentó un crecimiento de un 36 por ciento. La de los hogares un 47 por ciento. Y el mayor crecimiento lo experimentó el sector educacional, con un 135 por ciento. 
trimestre de 2006 el total de conexiones habría ascendido a 944.469, dando una penetración de 5,75 conexiones cada 100 habitantes, y 22,15 por ciento de hogares conectados ${ }^{15}$. Esto haría a Chile el país con mayor penetración de BA en la región.

El Gráfico $\mathrm{N}^{\circ} 3$ muestra la forma en que evolucionó esta penetración hasta 2006, distinguiendo entre conexiones conmutadas (las antiguas, que se conectaban a través de un modem en lugar de una llamada telefónica) y las dedicadas para BA (always on, exclusivas para la conexión, sea a través del par de cobre telefónico, como ocurre con la tecnología DSL; a través de fibra óptica, o a través del espectro, como el WLL, WiFi o WiMax):

\section{GRAFICO N ${ }^{\circ}$ 3: $\quad$ EVOLUCIÓN DE CONEXIONES DE ACCESO A INTERNET}

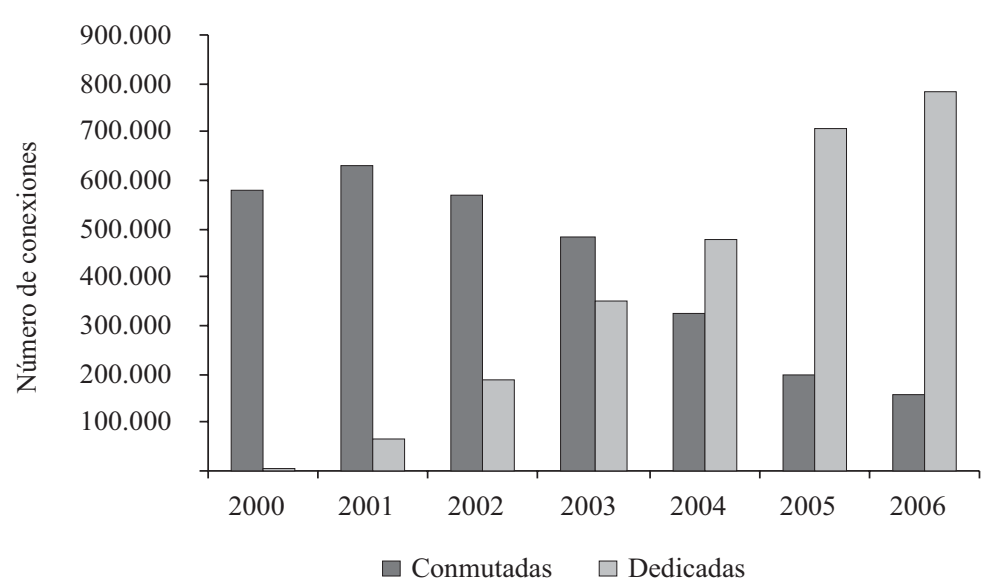

Fuente: Subtel (2007c).

${ }^{15}$ En Subtel (2007c) “Indicadores de Penetración de Internet” en http:// www.subtel.cl/prontus_subtel/site/artic/20070212/asocfile/20070212182348/ 2_indicadores_penetracion_internet.XLS. Los datos de penetración tienden a coincidir. Por ejemplo, la última encuesta del CEP señala que el 22,1 por ciento de los hogares de Chile declara tener alguna forma de conexión a Internet. Es interesante apuntar que el 38,3 por ciento de los hogares chilenos declara tener computador. Ahora bien, de éstos, el 57,6 por ciento declara tener alguna conexión a Internet. Este último porcentaje es igual al del total de hogares que declara estar conectados. Esto permite suponer la conclusión, bastante obvia por lo demás, de que las conexiones a Internet se encuentran en hogares en que hay computador (CEP, 2007). Por su parte, "Plan Estratégico de Desarrollo Digital 2007-2010", dado recientemente a conocer por el Comité de Ministros para el Desarrollo Digital, señala que en Chile hay cerca de un millón de hogares conectados. En http://www.economia.cl/aws00/Estatico/repositorio/c/R/X/ipVZIukVgIbyybk_Qx6S6YrA $=$.pdf. Este número no está lejos de los ya citados. 
Desde el punto de vista de su distribución geográfica, este acceso se distribuye de la forma que muestran los Gráficos $\mathrm{N}^{\circ} 4$ y N 5 .

GRÁFICO No ${ }^{\circ}$ : $\quad$ DISTRIBUCIÓN DE CONEXIONES POR REGIÓN A MARZO DE 2006

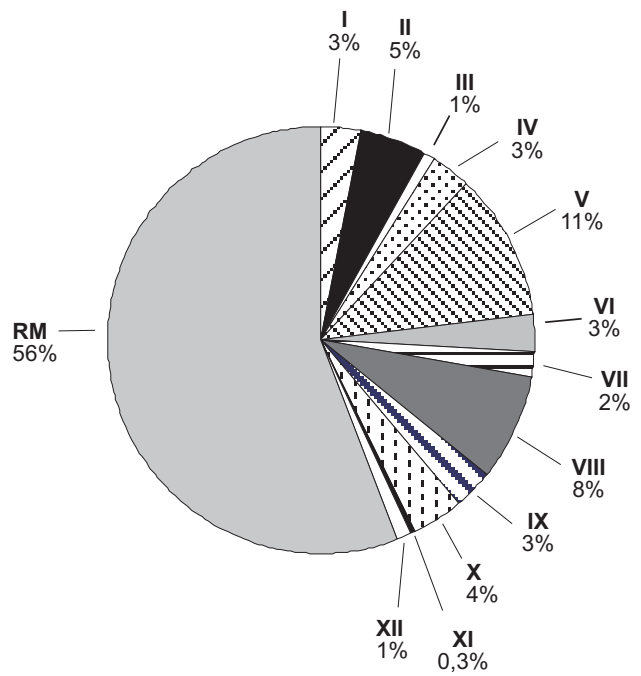

Fuente: Subtel (2007c).

GRÁFICO N ${ }^{\circ}$ 5: PENETRACIÓN DE CONEXIONES POR MODALIDAD DE ACCESO

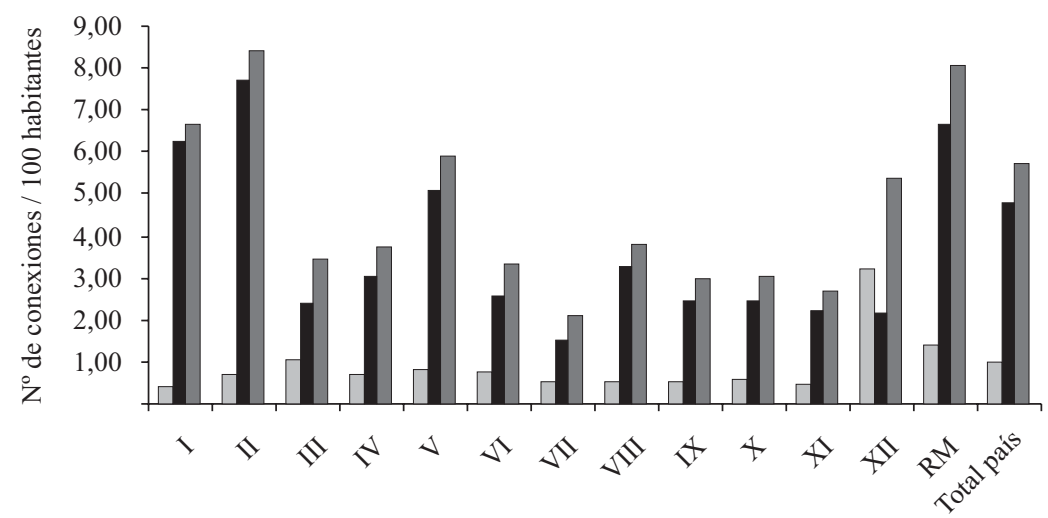

$\square$ Penetración acceso conmutado

Penetración acceso dedicado $\square$ Penetración total

Fuente: Subtel (2007c). 
Ahora bien, es obvio que esta notable expansión que ha experimentado la BA en Chile no tiene todavía la transversalidad socioeconómica que tiene la telefonía, en especial la móvil. Con la BA falta todavía camino por andar para materializar el principio de acceso universal. Todavía hay "brecha digital”. Para mostrar esto, se presentan a continuación algunos datos sobre conectividad en hogares y situación socioeconómica en Chile. La información es de 2000 y 2003, por lo que en el tiempo transcurrido desde entonces algunos cambios pueden haber ocurrido. Y nada dice esta información sobre la modalidad y velocidad de conexión, por lo que deben estar incluidas las conexiones conmutadas con el mínimo de 56 kbps, una conexión que no está a la altura de ninguna definición de BA. No obstante estas limitaciones, la información que sugieren los siguientes gráficos es interesante.

El Gráfico $\mathrm{N}^{\circ} 6$ relaciona acceso por hogar y quintiles de ingreso:

GRÁFICO No ${ }^{\circ}$ : BRECHA DIGITAL: HOGARES.

PORCENTAJE DE HOGARES CON ACCESO A INTERNET POR QUINTILES DE INGRESO

(CASEN 2000 Y 2003)

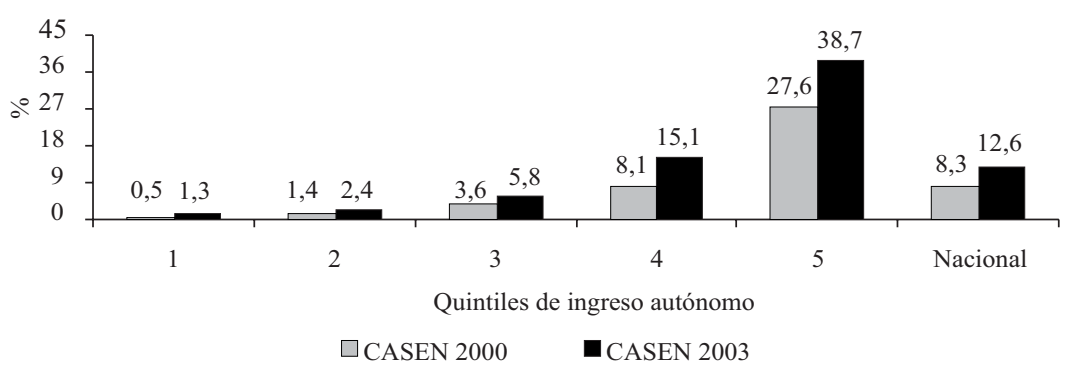

Fuente: Subtel, 2006.

Esto puede haber cambiado un tanto en estos últimos tres años, sobre todo teniendo en cuenta el dinamismo exhibido hasta ahora por este mercado, pero parece razonable suponer que no ha cambiado demasiado.

Con los mismos datos, el Gráfico $\mathrm{N}^{\circ} 7$ muestra el acceso no sólo en hogares, sino que le agrega el acceso en otros puntos, como bibliotecas, centros comunitarios, infocentros, etc. Aquí, obviamente, las diferencias por quintiles de ingreso se reducen: 

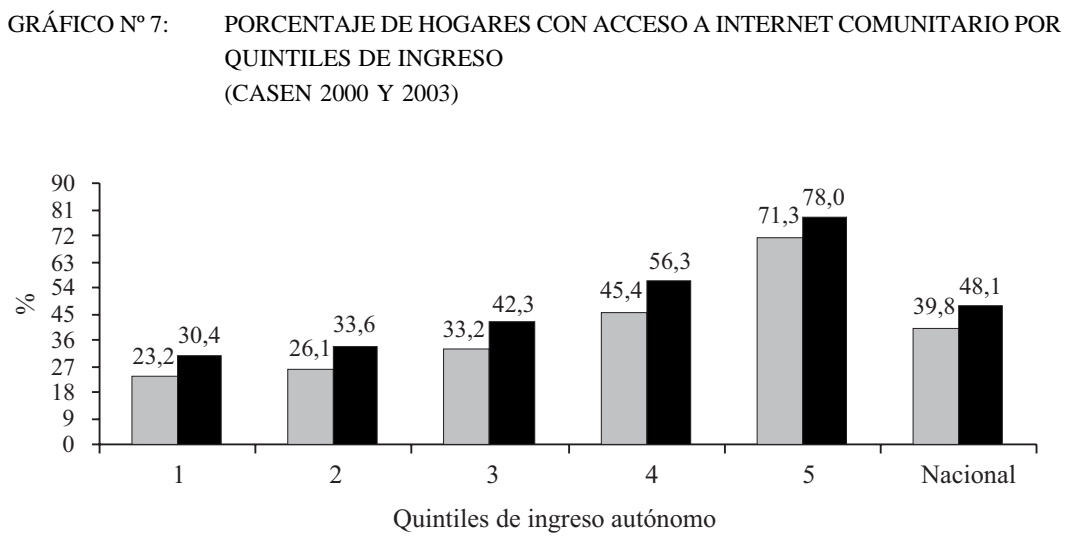

$\square$ CASEN 2000

- CASEN 2003

Fuente: Subtel, 2006.

Ahora bien, muchas personas acceden a Internet en sus lugares de trabajo. A este respecto, usando datos de 2002, el Gráfico $N^{\circ} 8$ muestra diferencias de acceso distinguiendo por la envergadura de las empresas. Naturalmente, aquí también hay diferencias:

GRÁFICO No 8: BRECHA DIGITAL: EMPRESAS.

TASA DE PENETRACIÓN DE INTERNET EN EMPRESA (\%)

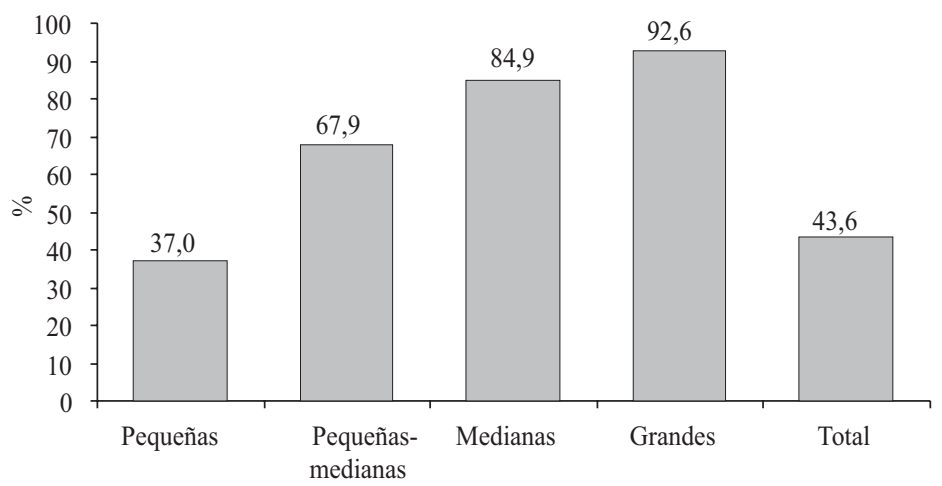

Fuente: Ministerio de Economía (2007). 
Cabe señalar que con datos más actualizados, de 2006, el Comité de Ministros para el Desarrollo Digital informó que el 68 por ciento de las empresas en Chile tiene conexión a Internet y el 64 por ciento a BA ${ }^{16}$.

No obstante las diferencias que estos datos muestran, se ha venido produciendo una expansión sostenida de la conectividad en Chile. La operación del Fondo de Desarrollo de las Telecomunicaciones (FDT) debe tener algo que ver con este aumento de conectividad en Chile. ¿Cuánto? Sería interesante saberlo, pero esta pregunta excede los límites de este trabajo. Pero es muy probable que influye con programas como, por ejemplo, el Proyecto de Conectividad para Escuelas Rurales, cuyo objeto es otorgar acceso a Internet, gratis por 3 años, a escuelas rurales de todo el país. A fines del año 2004 se llevó a cabo el concurso público. Como resultado, se financiaron proyectos para conectar con BA a 667 escuelas rurales de zonas aisladas y de pocos recursos, distribuidas en 155 comunas del país ${ }^{17}$.

La operación de otros subsidios también ha debido impactar, junto al FDT, en la expansión de la conectividad. Éstos se revisan a continuación.

\subsection{Otros subsidios a BA}

Estos subsidios están asociados a la esfera del Ministerio de Educación. Uno tiene que ver con la Dirección de Bibliotecas, Archivos y Museos (Dibam). Otro es el Programa Enlaces, del Centro de Educación y Tecnología del Ministerio de Educación.

4.1.1. Dibam. Ésta tiene un programa llamado BiblioRedes. Está presente en 378 bibliotecas públicas a lo largo del país, incluyendo los territorios insulares ${ }^{18}$. Todas ellas cuentan con equipamiento computacional y una red de banda ancha, que requiere en algunos casos conexión satelital. BiblioRedes tiene convenios con 292 municipalidades y recibe fondos del gobierno central asignados vía Ley de Presupuesto. En sus inicios contó con el aporte de US\$ 9,2 millones de la Fundación Bill \& Melinda Gates. Desde su inauguración, en 2002, BiblioRedes ha sido parte de la Campaña Nacional de Alfabetización Digital que promueve el gobierno. Y, según datos de éste, a la fecha se ha capacitado a más de 976.000 personas.

4.1.2. Enlaces. Este programa es parte de una política nacional para introducir tecnologías de la información y la comunicación en Chile. Su

\footnotetext{
${ }^{16}$ Ministerio de Economía (2007).

17 En http://www.subtel.cl/servlet/page?_pageid=58\&_dad=portal30\&_schema= PORTAL30.

${ }^{18}$ En http://www.biblioredes.cl/BiblioRed/Red+de+Bibliotecas/biblioteca.htm.
} 
objeto ha sido propiciar el acceso equitativo a las nuevas tecnologías, a través de la integración de redes y computadores en los establecimientos educacionales del país. Además, capacita a los profesores en estas materias ${ }^{19}$. Enlaces también ha sido parte de la Campaña Nacional de Alfabetización Digital del gobierno. Algunos hitos: a fines de los años 1990 recibió una donación de la empresa Telefónica para dotar de conexiones conmutadas a cuatro mil escuelas. Y desde el año 2002 viene dando un subsidio a la conectividad para las escuelas, el que ha permitido a muchas mejorar sus antiguas conexiones para disponer de BA. Los montos asignados para este subsidio alcanzan a alrededor de \$ 300 millones de pesos al año. Hasta ahora, Enlaces ha conectado a más de 6.300 escuelas y liceos. Ahora bien, el gobierno ha anunciado la intención de bajar el número de alumnos por computador y para los próximos años ha definido el siguiente plan: a) cuatro mil establecimientos municipales y subvencionados conectados a BA; b) bajar de 30 a 10 alumnos por computador, mediante la entrega de más de 200.000 nuevos equipos, y c) siete mil aulas del primer ciclo básico acondicionadas con proyector y computador portátil. Enlaces ha establecido alianzas con otras entidades para llevar adelante proyectos específicos. Por ejemplo, con la Fundación País Digital tiene dos: Chile@prende y TIC’s en Aula $^{20}$.

4.1.3. Fosis e Injuv. Ambas instituciones han destinado fondos a la apertura y operación de infocentros ${ }^{21}$.

Pasada esta rápida revista a la situación actual de BA en Chile, corresponde encaminarnos hacia terrenos de un carácter más normativo.

\section{5. ¿Cómo regular el acceso universal a la BA?}

La pregunta ahora es qué hacer para aplicar, regulatoriamente, el principio de acceso universal a la banda ancha. Como se ha visto, no hay que partir de cero, pues se ha avanzado en materias de conectividad. Y hay una experiencia de la que aprender para avanzar más, pues, como también se vio, todavía falta para que el acceso a BA sea verdaderamente universal. ¿Cómo hacerlo?

Intentaré contestar esta pregunta usando algunas de las caras o dimensiones que hemos visto del acceso universal en tanto principio regulatorio. Ellas son: subsidios, servicio público, interconexión y desagrega-

\footnotetext{
${ }^{19}$ En http://www.enlaces.cl/Contenido_Sitio.php?id_sitio=1.

${ }^{20}$ En http://www.chileaprende.cl/proyecto y http://tic.bligoo.com/tag/bienvenidaatic/, respectivamente.

${ }^{21}$ Para el Fosis, ver http://www.fosis.cl/opensite_20050908130559.asp, y para el Injuv, ver http://www.injuv.cl/modules.php?name=Content\&pa=showpage\&pid=18.
} 
ción. Me referiré sólo a dos de éstas: subsidios y desagregación. No me referiré a la interconexión, pues la obligación de interconectarse es una realidad de nuestra regulación y todo indica que lo seguirá siendo. Tampoco me referiré a la dimensión de servicio público, por las razones que inmediatamente siguen.

5.1. No al "servicio público" y sí a una regulación liviana tanto de BA como de sus aplicaciones

La dimensión de servicio público no debe aplicarse para honrar el principio de acceso universal a BA. Esto, pues, la idea de servicio público se aplica a una sola forma de telecomunicaciones, la que es calificada, precisamente, como "servicio público de telecomunicaciones". El ejemplo clásico aquí es la telefonía, alámbrica e inalámbrica. A los demás servicios en que la ley divide a las telecomunicaciones (como, por ejemplo, servicios de radiodifusión, servicios limitados de televisión, servicios intermedios y servicios complementarios) no se les aplican las obligaciones asociadas al servicio público. Por lo mismo, esta idea de servicio público es propia de una época pre convergencia, la época a la que pertenece nuestra actual legislación. Se trata de una época anterior a la masificación de la tecnología digital y a la convergencia que ésta permite e incentiva, una época en que era fácil distinguir entre distintos "servicios” y darles a cada uno una regulación específica. El servicio público, por tanto, es propio de una época tecnológicamente divergente, no convergente. Y, como sabemos, BA es el medio de la convergencia. Por otra parte, sería dañino forzar la idea de servicio público para aplicarla a la BA. Esto, por cuanto esa calificación implica un conjunto de obligaciones y, como lógica contrapartida, una pesada carga regulatoria, carga que no se debe poner sobre la BA.

Esa pesada carga regulatoria se manifiesta en el hecho de que los servicios de telecomunicaciones calificados como "públicos" están sometidos al más estricto régimen de autorización: requieren de concesión, la que se otorga por decreto supremo. Además, están sujetos a otras obligaciones, como las que pesan sobre el servicio público telefónico: distribuir a cada uno de los suscriptores, a lo menos cada dos años y sin costo para éstos, una guía telefónica actualizada, y los años en que no corresponda distribuir la guía, se debe distribuir un anexo que actualice la información; se debe descontar del cargo fijo mensual, a razón de un día por cada 24 horas o fracción superior a 6 horas, toda suspensión, interrupción o alteración del servicio telefónico que exceda de 12 horas por causa no imputable al suscriptor; sólo puede cobrarse por visitas de diagnóstico que estén respaldadas por un documento o guía de trabajo, debidamente firmado por el 
suscriptor local, siempre que el desperfecto detectado se localice en instalaciones telefónicas interiores o equipos telefónicos locales suministrados por terceros y no cubiertos por un contrato de mantención con la compañía telefónica local; se debe aceptar el pago atrasado de la cuenta única telefónica, sin perjuicio de los intereses que aplique cada proveedor de servicio, cuyos montos serán incluidos en la cuenta única telefónica más próxima; entre otras muchas obligaciones de distinto tipo ${ }^{22}$.

La experiencia y la literatura concuerdan en el hecho de que la BA se ha desarrollado bajo una intensidad regulatoria bastante menor que la que ha acompañado a la telefonía o a la radiodifusión, y también concuerdan en el hecho de que esta baja intensidad regulatoria ha tenido que ver con el vertiginoso desarrollo de la BA. Hay que seguir así: con la mínima regulación posible. Por esto, la idea de servicio universal, con su pesada mochila regulatoria, debe aquí ser evitada. Al respecto es interesante la siguiente nota de Neuchterlein y Weiser (2005: 133) sobre la misma baja intensidad regulatoria a que está sometida la BA en Estados Unidos:

[los] acuerdos de peering y de tránsito carecen completamente de regulación. Ni la FCC ni otra autoridad gubernamental regula los precios que una red troncal puede cobrar a una más pequeña por servicios de tránsito, tampoco obligan a esos proveedores troncales a ningún tipo de interconexión. Este enfoque desregulatorio ha funcionado hasta ahora porque ninguno de estos proveedores troncales ha crecido lo suficiente como para dominar el mercado y cobrar precios ineficientemente altos por transitar. En general, prevalece un equilibrio competitivo en el mercado, donde las grandes redes troncales 'compiten por el negocio del tráfico de las pequeñas redes troncales a fin de aumentar ingresos', y dicha competencia ha mantenido los precios bajos.

Por su parte, la baja intensidad regulatoria a que también está sometida la BA en Chile se manifiesta en el hecho de que la conexión a ella que es dedicada no calza en ninguno de los "servicios" que distingue la Ley 18.168. Ahora, la BA cuya conexión es conmutada calza en la clasificación de servicio "complementario", pues es un servicio "adicional" que se proporciona "mediante la conexión de equipos" a las redes públicas de telecomunicaciones. En el primer caso, el de las conexiones dedicadas (cada día más comunes), la BA se considera simplemente como un "servicio de telecomunicaciones", en los términos de la definición general del Art. 1 de la Ley 18.168: "Para los efectos de esta ley, se entenderá por telecomunicación

${ }^{22} \mathrm{Al}$ respecto, ver el Decreto Supremo 425 de 1996, que contiene el Reglamento del Servicio Público Telefónico. 
toda transmisión, emisión o recepción de signos, señales, escritos, imágenes, sonidos e informaciones de cualquier naturaleza, por línea física, radioelectricidad, medios ópticos u otros sistemas electromagnéticos”. No es un servicio "público", y no está sometido a ningún régimen especial de regulación, salvo a la obligación de cumplir alguna normativa "técnica" mínima. Como se argumentará luego, esta regulación mínima no debería cambiarse. Al contrario, debería extenderse no sólo a la conexión a BA, como es ahora, sino que ampliarse lo más posible a sus aplicaciones (a VoIP, por ejemplo).

En el segundo caso, el de las conexiones conmutadas, la mano regulatoria tampoco ha sido pesada. Esta forma de conexión se ha tenido como un servicio específico de telecomunicaciones: un "servicio complementario”, que tampoco está sometido a un régimen especial. Si bien está calificado específicamente por la ley, no se exige autorización por parte de la autoridad regulatoria y se puede prestar indefinidamente. $\mathrm{Al}$ igual que en el caso anterior, sólo debe cumplir con algunas disposiciones “técnicas" fijadas por la Subtel ${ }^{23}$.

Esta mano regulatoria liviana debe mantenerse en el futuro, y debe hacerse cada vez más liviana. Debería extenderse, además, a las aplicaciones específicas sobre BA. La telefonía VoIP es una de éstas. Al respecto, las señales regulatorias en Chile no son demasiado auspiciosas. Esto, por cuanto el gobierno ha propuesto que VoIP sea calificado como "servicio público" en el caso de que uno de los extremos de la llamada VoIP esté conectado a una red de servicio público telefónico. Ha habido dos consultas públicas sobre VoIP, una de 2004 y otra de 2006. Ambas hablan de "servicio público" para VoIP que accede a una red pública. La primera habla de "servicio público de telecomunicaciones de voz" y la segunda de "servicio público de voz sobre Internet”. Es decir, propone calificarla como un "servicio" específico y, no sólo esto, propone que este servicio sea "público". En esto, las propuestas del gobierno no avanzan hacia la lógica de la convergencia que encarna la BA, sino que parecen seguir atrapadas en la lógica divergente de nuestra tradición histórica ${ }^{24}$. ¿Por qué aplicarle a VoIP

${ }^{23}$ Esta regulación “técnica” está constituida por las siguientes normas: Resolución Exenta 1.483 de 22/10/1999, Fija Procedimiento y Plazo para Establecer y Aceptar Conexiones entre ISP; Resolución Exenta 698 de 30/06/200, Fija Indicadores de Calidad de los Enlaces de Conexión para Cursar el Tráfico Nacional de Internet y Sistema de Publicidad de los Mismos; Resolución Exenta N 669 de 01/06/2001, Fija Indicadores de Calidad del Servicio de Acceso a Internet y Sistema de Publicidad de los Mismos, modificada por Resolución Exenta 1.493 de 12/11/2001.

${ }^{24}$ La primera consulta pública, de 2004, está en http://www.subtel.cl/pls/portal30/ docs/FOLDER/WSUBTEL_CONTENIDOS_SITIO/SUBTEL/CONSULTA_PUBLICA/CONSULTA/DOC_CONSULTA_PUB_VOIP/DOCUMENTO_DE_CONSULTA_VOIP.PDF. Y la segunda está en http://www.subtel.cl/pls/portal30/docs/FOLDER/WSUBTEL_CONTENIDOS_SITIO/ SUBTEL/CONSULTA_PUBLICA/CONSULTA/CONSULTA_VOIP/CONSULTA_PUBLICA_VOIP_ 201206.PDF. 
la lógica pre convergente de la telefonía, y no la lógica más convergente de la simple transmisión de datos? ¿Por qué, en otras palabras, a VoIP se le da tanto de telefonía y tan poco de IP?

Estas preguntas se han hecho en Estados Unidos en la forma de otra pregunta: ¿VoIP es un servicio de información o uno de telecomunicación? En el primer caso, la regulación es mucho más liviana que en el segundo. A mi juicio, si se quiere mantener una mano regulatoria liviana sobre la BA, hay que pensar las aplicaciones sobre ella con la lógica propia de BA, es decir, como transmisión de datos, simplemente.

De alguna manera, la resolución que el Tribunal de Defensa de la Libre Competencia (TDLC) dictó en octubre de 2006 en un caso sobre VoIP, se hace estas mismas preguntas y deja abierta la posibilidad de regular VoIP de un modo más cercano a Internet que a la telefonía. Si bien los considerandos de la resolución en que el TDLC avanzó dicha posibilidad fueron declarados "improcedentes" por la Corte Suprema en su sentencia de 4 de julio de 2007, en la que resolvió una reclamación contra lo resuelto por el TLDC, siguen siendo interesantes desde el punto de vista de la discusión a que apunta este artículo ${ }^{25}$.

El TDLC fue enfático en la necesidad de una regulación liviana para VoIP: “[...] la telefonía IP no debiera ser objeto de una intervención estatal importante, toda vez que la competencia en el mercado debiera tender a garantizar estándares apropiados de calidad y a establecer la relación entre los distintos precios y calidades. Lo anterior, de no mediar prácticas restrictivas de la libre competencia”.

Incluso en el caso de que sea calificado de "servicio público", el TDLC apeló a una regulación liviana: “[...] en el caso de que la telefonía IP prestada sobre banda ancha sea finalmente considerada por la autoridad competente como un servicio público de telecomunicaciones, la regulación que efectivamente se le aplique debe ser la mínima necesaria y deberá limitarse a reglar el régimen concesional que se utilice, a asegurar que los prestadores de este servicio cumplan con estándares técnicos mínimos, con el deber de interconexión con otros servicios públicos de telecomunicaciones del mismo tipo — respetando las normas técnicas pertinentes- y normar lo relativo a los cargos de acceso y la asignación de numeración telefónica,

${ }^{25}$ La resolución del TDLC está en http://www.tdlc.cl/db_images/sentencias/ 45411f978d854_Sentencia-45-2006.pdf. La Corte Suprema no modificó el fondo de lo resuelto por el TDLC. Rebajó, eso sí, el monto de las multas impuestas originalmente por el TDLC y declaró improcedentes los considerandos $72^{\circ}$ al $81^{\circ}$. Esto último, por cuanto la Corte consideró que el TDLC "carece de competencia para pronunciarse acerca de la naturaleza jurídica de los servicios de telefonía IP a efectos de la aplicación de la Ley General de Telecomunicaciones”. Esta sentencia está en http://www.poderjudicial.cl/ index2.php?pagina1=causas/esta402.php?h=AAANmYAAPAAA8jJAAR. 
considerando la posibilidad de la portabilidad del número, todo ello para que pueda existir una fluida comunicación entre los usuarios de las concesionarias de telefonía IP y los de las concesionarias del servicio público telefónico y una mayor competencia en el mercado. Finalmente, la regulación que eventualmente se adopte debiera hacerse cargo de la tendencia a la convergencia tecnológica, regulando la industria de modo tal que no se produzcan subsidios cruzados o discriminaciones entre las diversas compañías que prestan servicios de telefonía; que se garantice la mayor libertad posible para ingresar al mercado, y se impidan las conductas que dificulten artificialmente dicha entrada".

Menos enfático fue el TDLC en relación con el carácter de la tecnología VoIP. Aquí se hizo la pregunta básica: ¿Cómo calificarlo según la tipología de servicios que enumera la Ley 18.168? Al respecto, señaló: “Que la Voz sobre Protocolo IP es, indudablemente, un servicio de telefonía, en gran medida sustituto de la telefonía tradicional, que es prestado por medio de una tecnología diferente y, en el caso de autos, aprovechando el acceso a Internet por banda ancha. Lo anterior plantea el problema de resolver cómo enmarcarlo en nuestro ordenamiento jurídico, de manera que se desarrolle de manera eficiente, sin encontrar barreras innecesarias que dificulten ese desarrollo y, a la vez, evitando que se generen distorsiones en el mercado que impidan el mayor beneficio social posible". Y en otro pasaje repitió esta idea: "[...] en opinión de este Tribunal, el debate de autos en torno al régimen jurídico que ha de aplicarse a la telefonía IP sobre banda ancha es expresión de la dificultad de encuadrarla jurídicamente en las distintas categorías de servicios de telecomunicaciones, e incluso de la pertinencia de considerar esta telefonía como un servicio de telecomunicaciones en lugar de reputarla una aplicación de Internet que no debería ser regulada más que cualquier otra. Dicha dificultad ha sido acentuada por la falta de definición al respecto de las autoridades regulatorias, en lo relacionado con la telefonía IP”.

Aunque la Corte Suprema consideró estas reflexiones del TDLC como "improcedentes", la pregunta quedó planteada: ¿VoIP como servicio público o como aplicación de Internet? Este trabajo avanzará la hipótesis de que el principio de acceso universal aplicado a la BA exige lo segundo.

Creo razonable interpretar este fallo como una sugerencia para que el gobierno reconsidere su postura original y se abra a la posibilidad de regular menos la tecnología VoIP. Como parece mostrarlo la experiencia, los triple play son un buen incentivo para conectarse. Al respecto, hace dos años Neuchterlein y Weiser (2005: 144) escribieron: 
La creencia general señala que cada vez más consumidores residenciales querrán contratar con un mismo proveedor el mítico "triple play" de los servicios de comunicaciones: (i) un servicio de voz confiable, (ii) acceso a Internet de banda ancha, y (iii) programación de video de alta calidad. Como suele suceder con la creencia general, esta puede develarse verdadera o falsa. Hasta ahora, sin embargo, el mercado lo ha tomado seriamente. Así también la han tomado las grandes empresas telefónicas, algunas de las cuales han prometido, a una comunidad financiera todavía algo escéptica, que ellas enfrentarán este desafío destinando varios billones de dólares durante los próximos años al despliegue de redes de fibra para los hogares.

Hay que facilitar, entonces, el desarrollo de VoIP, pues, como lo enseña la experiencia que señala el párrafo anterior, esa aplicación puede ser una especie de killer application para la masificación de BA y, a través de esta expansión, para materializar el principio de acceso universal a su respecto. Para esto, hay que ponerle encima una mano regulatoria muy liviana. La calificación de "servicio público" que pretende darle el gobierno incluye, necesariamente, una mano regulatoria demasiado pesada. Junto a esta necesidad de liviandad, también hay que pensar en un buen sistema de subsidios. A esto se dedica lo que inmediatamente sigue.

\subsection{Subsidios: mirar a San Expedito}

Como se vio más arriba, el mecanismo de subsidios fiscales en materia de telecomunicaciones es antiguo en nuestra regulación: viene desde el siglo XIX. Y hay buenas razones para mantenerlo. Hoy el quicio de este mecanismo es el Fondo de Desarrollo de las Telecomunicaciones (FDT).

Parece razonable ir trasladando el foco del FDT desde la telefonía a la conectividad de BA. Y parece razonable, también, seguir haciéndolo mediante la conexión de escuelas. Esto reconoce la poderosa relación que existe entre BA y educación, y la idea de igualdad que, como principio de moralidad política, subyace a esa relación. Al respecto, sobra decir que aquí se requiere una coordinación fluida entre la Subtel y el Ministerio de Educación, especialmente con su proyecto Enlaces. También es importante, por supuesto, dejar el mayor campo posible a la iniciativa privada, la que con iniciativas como Chile@prende o la iluminación de la ciudad de Salamanca, por ejemplo, pueden ayudar a ir materializando el principio de acceso universal. 
Manteniendo un foco en Educación, el FDT puede unirse a otros esfuerzos fiscales destinados a este objetivo. La experiencia comparada y alguna chilena parecen mostrar el beneficio socialmente alto de proveer conectividad inalámbrica, iluminando zonas. El caso de Salamanca —una iniciativa privada - es pionero en Chile. Hay otro más reciente, en Viña del Mar. Se trata de la población "San Expedito" del barrio "Forestal” de esta ciudad. 240 familias recibieron viviendas por parte del programa Vivienda Social Dinámica Sin Deuda, del Serviu. Junto con las viviendas, la población fue dotada con un infocentro e iluminada con WiFi, permitiendo conectarse a BA por la suma de 2 mil pesos al mes. Esta iniciativa contó con aportes privados ${ }^{26}$.

Ésta es una iniciativa que podría replicarse y expandirse conjuntamente por la Subtel y el Minvu. Una posibilidad para hacerlo es el programa "200 Barrios", que forma parte de las "100 Medidas" del actual gobierno. En el marco de este programa, "se seleccionaron los 200 barrios de alta concentración de deterioro urbano y vulnerabilidad social, en los que se realizará el programa de intervención". Un elemento de esta intervención podría ser conectar el barrio iluminándolo ${ }^{27}$. La esperanza tras esto, como parecería sugerirlo la experiencia de Salamanca, es que la conectividad incentive a las personas a dotarse de computadores y a capacitarse digitalmente. Tanto más si esta conectividad viene con aplicaciones que se valoran especialmente, como VoIP y televisión. Aquí se trata de conectividad inalámbrica. Esto sugiere preocuparse del espectro radioeléctrico.

\subsection{Cuidar el espectro}

Aunque parezca obvio, es importante administrar hoy el espectro radioeléctrico pensando en las necesidades de mañana. Al escribir estas líneas, la compañía Apple presentó un nuevo producto: iPhone y, de alguna manera, mostró el futuro de las telecomunicaciones. Un verdadero símbolo de la convergencia: un aparato portátil que sirve de teléfono, de receptor de

\footnotetext{
${ }^{26}$ Más detalles sobre ella en http://www.serviuvalpo.cl/noticias_det_ok.asp?id=284 y en http://www.mercuriovalpo.cl/prontus4_noticias/antialone.html?page=http:// www.mercuriovalpo.cl/prontus4_noticias/site/artic/20061230/pags/20061230021511.html.

${ }^{27}$ En http://www.gobiernodechile.cl/100/meta/100dias.pdf. Durante los años 2007 y 2008, la Subtel anunció subsidios destinados a construir un infocentro de acceso a Internet y plazas digitales al interior de cada uno de los 200 barrios. Además, subsidiará una oferta de servicios con facilidades para los hogares de cada población beneficiada, a fin de que las familias puedan contratar una conexión domiciliaria pagando tarifas inferiores a los valores que ofrece hoy el mercado. En http://www.subtel.cl/ prontus_subtel/site/artic/20070803/pags/20070803162549.html.
} 
televisión, videos y música, y de computador conectado a $\mathrm{BA}^{28}$. No parece descabellado imaginar que un aparato de estas características encarnará en el futuro el proceso de convergencia que experimentan las telecomunicaciones. En relación con esto, es significativo el siguiente texto de The Economist sobre sir Tim Berners-Lee, creador de la Word Wide Web en 1991:

Bajo el liderazgo de sir Tim, el W3C —el órgano perteneciente al MIT que define los estándares para la red, que él encabeza desde 1994- ha lanzado una iniciativa de red móvil para adaptar los estándares de la red a fin de que la información sea más accesible por medio de aparatos móviles. Sir Tim espera que dichos estándares ayuden a hacer más accesible la riqueza de la red al próximo billón de usuarios. Esto debería ayudar a extender sus beneficios a la mayor parte de la población mundial (p. 7).

Esta movilidad es inalámbrica, por lo que la expansión que se le augura demandará espectro radioeléctrico. Ésta podrá ser a través de tecnologías como, por ejemplo, la telefonía móvil de "tercera generación” (3G), WiFi o WiMax, todas disponibles hoy en Chile. Cualquiera sea la o las tecnologías móviles que prevalezcan en el futuro, el hecho es que necesariamente requerirán espectro. Esto impone la necesidad de que la política regulatoria sobre el espectro tenga presente ese probable futuro y se distribuya este recurso con sabiduría, siempre intentando maximizar la eficiencia con que se le usa. Esto contribuirá a la posibilidad de expandir la conectividad a BA usando redes inalámbricas, materializando, al mismo tiempo, el principio de acceso universal. En estos momentos, Chile enfrenta una decisión concreta en estas materias: la definición del estándar para la radiodifusión televisiva digital. Esta decisión debería tomarse teniendo en cuenta la posibilidad de maximizar la eficiencia en el uso del espectro radioeléctrico.

Sobre la importancia creciente de la telecomunicación inalámbrica respecto de $\mathrm{BA}$, se ha escrito:

Una oportunidad más elemental y estructural para crear una infraestructura abierta de banda ancha está apareciendo en el ámbito inalámbrico. Para saber cómo hacerlo, primero tenemos que reconocer que las oportunidades de controlar la infraestructura de banda ancha en general no se encuentran distribuidas parejamente a lo largo de la infraestructura de redes. Las vastas porciones de la red tienen múltiples caminos paralelos, sin puntos claros de estrangulamiento. El ob-

${ }^{28}$ Ver, al respecto, The Economist (2007a) y (2001). 
vio y principal punto de estrangulamiento en el transporte físico de bits a través de Internet está en la última milla de la mayoría de los barrios, salvo los más conectados. Es decir, el primer cuello de botella es el alambre o cable que conecta los hogares o las pequeñas oficinas a la red. Es aquí donde los operadores de cable y telefonía local controlan el mercado. Es aquí donde los altos costos de abrir las calles, tender fibra, o de cablear paredes, levantan una barrera prohibitiva para la competencia. Y es aquí, en la última milla, donde las posibilidades inalámbricas no sujetas a licencia ofrecen la mayor promesa para otorgar una infraestructura física común, de propiedad de sus usuarios, compartida como commons, y privando a cualquiera de un cuello de botella desde donde controlar qué persona dice qué a tal otra. (Benkler, 2006: 402.)

Esta reflexión sobre la última milla como red alámbrica, y los "puntos de estrangulamiento" que pueden surgir en ella, nos lleva a la cara quizás más polémica que puede asumir el principio de acceso universal: la desagregación.

\subsection{Desagregación de redes}

Desde un punto de vista económico, la desagregación es una cuestión difícil, pues no hay claridad de que al imponerla se originen ganacias netas de bienestar. Acto seguido, si se llega a la conclusión de que sí se originan, hay que decidir a quién imponer la obligación de desagregarse: ¿a todos los titulares de redes o sólo al dominante?

Los países más avanzados en BA y con mayor cobertura han ensayado alguna forma de desagregación del bucle local. Esto es así desde la Unión Europea hasta la República de Corea. No se me escapa el hecho de que cada experiencia es distinta y que no se puede, por tanto, extrapolar absolutos. Cada experiencia tiene sus particularidades: distinto tamaño y características de sus mercados de telecomunicaciones, distintos grados de penetración de la telefonía fija, la existencia de un operador dominante de propiedad estatal que, al privatizarse, es desagregado. Pero, no obstante tantas particularidades, es interesante el hecho de que la mayor conectividad a BA se ha venido produciendo en contextos que experimentaron alguna forma de desagregación.

En Chile, algunos consideran que la inexistencia de desagregación tiene que ver con los precios todavía relativamente altos que pagamos por BA. Engel y Navia (2006: 200-201), por ejemplo, han escrito: 
El precio del acceso a Internet de banda ancha viene cayendo muy rápido en todo el mundo. Por ejemplo, en los Estados Unidos recientemente se anunciaron ofertas de 15 dólares, equivalentes a ocho mil pesos mensuales. En Chile, en cambio, el precio promedio supera los 30 mil pesos en igual fecha $\mathrm{y}$, lo que es más grave, el principal proveedor (CTC) pareciera no estar interesado en desarrollar el negocio, pues ofrece banda ancha a menos del $10 \%$ de sus clientes y con una velocidad muy inferior al máximo posible. [...] Este medio es tan poderoso que permite hacer llamadas telefónicas a un precio muy inferior al que se paga actualmente. El precio por Internet no depende de la duración de las llamadas ni de cuán lejos está el destinatario, es cosa de pagar un monto fijo mensual y se puede realizar llamados con la frecuencia que uno desea a los lugares que quiera, mientras ambos extremos estén conectados. La falta de entusiasmo de CTC por desarrollar este negocio se explica por la amenaza que representa Internet de banda ancha para la telefonía. Como es dueña de la mayor parte de los 3,5 millones de líneas de cobre necesarias para llevar la banda ancha a los usuarios, esta empresa dominante puede limitar seriamente el desarrollo de nuevos negocios que utilizan la banda ancha. En situaciones como ésta, el rol del regulador — la Subtel, en este caso- es dar acceso a los (sic) través de los cables de cobre de CTC a todas las empresas que deseen utilizarlos, asegurando que éstas paguen un precio que compense a la compañía por su inversión, evitando al mismo tiempo que Telefónica utilice su posición privilegiada para entorpecer el desarrollo de nuevos negocios que utilizan estas líneas. Este proceso regulatorio se conoce como “desagregación de redes”. La desagregación de redes que ha intentado la Subtel no ha funcionado. Ésta ha protegido los intereses comerciales de CTC y no logra dar confianza a las empresas que no serán “expropiadas” por Telefónica, por lo cual estas últimas no han hecho las inversiones necesarias para proveer servicios utilizando las líneas de cobre. No es primera vez que la introducción de nuevas tecnologías en telecomunicaciones se ve obstaculizada por debilidades regulatorias. Una situación similar ocurrió a fines de los 90, cuando el acceso a Internet era por vía telefónica y la Subtel demoró varios años en regular las tarifas de manera diferente a como regulaba las llamadas telefónicas de voz. Fijar tarificaciones diferentes se justificaba económicamente porque, a diferencia de las conversaciones telefónicas, el costo de las conexiones de Internet por vía telefónica no depen- 
de de la duración de la conexión. La demora de la Subtel se tradujo en que durante varios años CTC cobró la conexión por minuto, lo cual retrasó el desarrollo de Internet en Chile.

El precio relativamente alto que por BA pagaríamos en Chile aparece reflejado en el Gráfico $N^{\circ} 9$ dado a conocer hace poco por el Ministerio de Economía, en el que se comparan tarifas de BA residencial con velocidades desde $1 \mathrm{Mb}$, en precios en dólares ajustados por PPP:

GRÁFICO N 9: TARIFAS BANDA ANCHA RESIDENCIAL EN \$US PPP CON VELOCIDAD DE 1MB O SUPERIOR (Año 1999)

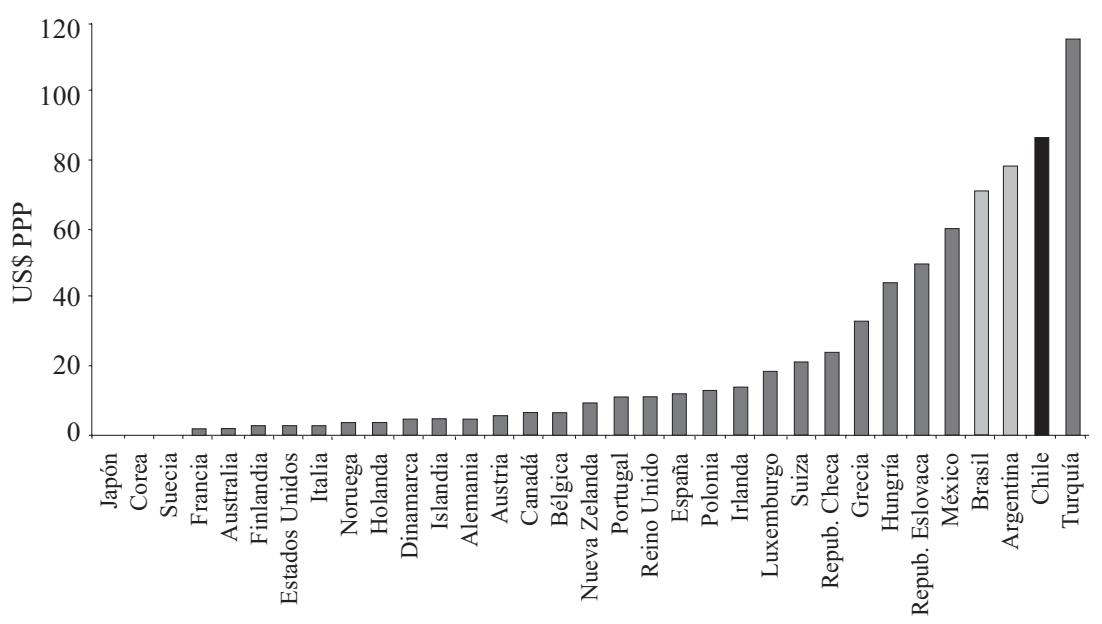

Nota: Las tarifas de Chile, Argentina y Brasil son de junio de 2007, sin IVA.

Este precio relativamente alto de BA en Chile también apareció en una tabla comparativa que publicó en 2003 la International Telecommunications Union. Ver dicha tabla en el Anexo.

Fuente: Ministerio de Economía (2007).

En Chile, la desagregación se discutió en 2004 a raíz de una consulta pública que al respecto hizo el gobierno. Fue la consulta sobre "Marco de Referencia Reglamento para Servicios de Desagregación de Redes"29. No debe olvidarse que esta consulta estuvo precedida por una intensa activi-

${ }^{29}$ En http://www.subtel.cl/pls/portal30/docs/FOLDER/wSUBTEL_CONTENIDOS_SITIO/SUBTEL/CONSULTA_PUBLICA/CONSULTA/MARCO_REFERENCIA_SSDR/ MARCO_REFERENCIA_REGLAMENTO_SSDR.PDF. 
dad sobre la materia de la Comisión Resolutiva de la antigua institucionalidad antimonopolios. Sus Resoluciones 394 de 1993 y 515 de 1998 dispusieron que la regulación de los servicios de conmutación y/o transmisión de señales provistas como circuitos privados debe tender a facilitar el suministro desagregado de las facilidades de red local para permitir la introducción de mayor competencia en el servicio telefónico local. También la Resolución Nº 611 de 2001, que señaló que debería procurarse la remoción oportuna de cualquier obstáculo artificial para la libre competencia, ya sea que éste se origine en el manejo de la numeración telefónica, en la asignación de frecuencias del espectro radioeléctrico o en el acceso de los operadores de telecomunicaciones a las innovaciones tecnológicas que se incorporen a la red pública telefónica, entre otros factores de entorpecimiento. Y, en fin, la Resolución No 686 de 2003, que dispuso que, para profundizar la competencia, es fundamental garantizar la efectiva desagregación de redes, imponiéndole al regulador la obligación de corregir las distorsiones que, en relación con esta materia, se han producido en el mercado del servicio telefónico local.

No obstante estos antecedentes, y no obstante la consulta y el impulso inicial que ella reflejaba por parte del gobierno, después de 2004 no se ha vuelto a discutir públicamente el asunto, y el gobierno no parece, por ahora, interesado en retomar la discusión.

En algún sentido, este silencio puede explicarse porque es una discusión nada de fácil: la desagregación tiene también serios oponentes. Un buen ejemplo es el ministro de la Corte Suprema de Estados Unidos, Stephen Breyer (2004: 9-10):

[...] los cables de cobre no deberían compartirse porque es mucho más eficiente construir nuevas conexiones inalámbricas baratas, que pagar los tres millones de dólares necesarios para mantener el cableado existente. Pero las normas de la FCC llevarían a las nuevas empresas a arrendar los cables existentes, en vez de construir sistemas inalámbricos nuevos, ya que pagarían menos por ese arriendo que por una nueva construcción. En efecto, las normas de la FCC incentivarán a las nuevas empresas a arrendar el sistema completo de un operador existente, generando una comunidad universal en lugar de competencia universal. Al insistir en que un nuevo entrante reciba las ventajas inmediatas de las innovaciones ahorradoras de costos de un operador existente, esas normas desincentivan la innovación y la inversión. Y por razones que no voy a profundizar aquí, creo que puedo demostrar —si las 
cifras son más realistas - que un operador existente carecería de los incentivos económicos necesarios para invertir e innovar. En el fondo, mediante la creación de un precio "compartido” para cada elemento en un sistema existente, precio que es igual o más bajo que el precio asociado a la creación de una nueva facilidad independiente, esas normas tienden a un sistema en que la fijación tarifaría suplanta, y no promueve, la competencia.

Sería interesante sostener esta discusión de una forma atenta a la situación chilena ${ }^{30}$.

\section{Conclusión}

Este trabajo ha intentado pensar el principio de acceso universal respecto de la BA. Este principio es antiguo en nuestra regulación de las telecomunicaciones. Además de responder a ideas de moralidad política, como la igualdad, el principio de acceso universal está relacionado con la economía de redes que caracteriza a las telecomunicaciones.

En nuestra historia, la regulación del principio de acceso universal ha tenido varias caras, y las sigue teniendo. Estas caras han sido:

- $\quad$ subsidios fiscales,

- $\quad$ obligación de "servicio público” y

- $\quad$ obligación de interconexión.

Más recientemente, se ha discutido la posibilidad de otra cara más:

- $\quad$ obligación de desagregación.

Para la BA, este trabajo propone que el principio de acceso universal sea regulado con sólo algunas de estas caras: subsidios, interconexión y desagregación. No, en cambio, con la noción de “servicio público”. Esto, porque la BA necesita estar sometida a una baja, la más baja posible, intensidad regulatoria. Y la idea de "servicio público", como lo demuestra la regulación a que ha estado sometida la telefonía, conlleva muchas obligaciones. Demasiada regulación, en circunstancias que la BA sólo necesita

30 Algunos antecedentes hay como, por ejemplo, González y Gómez-Lobo (2006). Ellos concluyen que, atendidas las características del mercado chileno, la obligación de desagregar no se justifica. 
una mínima regulación, la mano más liviana que sea posible. Por esto, la propuesta de regular VoIP como un "servicio público" es muy discutible: a las aplicaciones de BA, como la transmisión de voz en el caso de VoIP, se les debe aplicar la lógica de BA. Todas las aplicaciones que van sobre la BA deberían ser consideradas como datos. Así, además, hay más posibilidades de que se transformen en killer applications.

La obligación de interconexión existe hoy en nuestra legislación, y lo más probable es que seguirá existiendo. Por eso este trabajo no se detiene en ella. Sí dice algo sobre subsidios y desagregación.

Respecto de los subsidios, es positivo el hecho de que estén abandonando la telefonía y se estén concentrando en la BA. También es positivo que se concentren en las escuelas pobres urbanas y rurales, y en otros centros de acceso comunitario. Positiva, además, parece la idea que considera el gobierno en el sentido de "iluminar" proyectos de mejoramiento urbano. La conectividad inalámbrica es una alternativa interesante a explorar. Para esto se debe cuidar el espectro radioeléctrico. La forma en que se regule la transición a la televisión digital será un buen indicador de ese cuidado $^{31}$.

Respecto de la desagregación, es algo que se puede discutir. No es una cuestión fácil, pero vale la pena pensarla. Hay experiencia comparada de la que se puede aprender. Tal vez la desagregación sea la oportunidad de terminar con el carácter asimétrico de nuestra regulación de telecomunicaciones. Se le puede imponer la obligación de desagregar al dominante, y luego se lo libere de su régimen excepcional. O, quizás, para prestar atención a la advertencia del juez Breyer citada más arriba, se pueda liberar al operador dominante con la única obligación de interconectarse, sin obligaciones de desagregación. Esto hay que discutirlo. Mientras tanto, se podría avanzar con las caras del principio de acceso universal respecto de BA que parecen más claras: rechazar la noción de "servicio público" para la BA y sus aplicaciones (porque el servicio público tiene una intensidad regulatoria que le es naturalmente propia) y subrayar el mecanismo de subsidios y las obligaciones de interconexión.

${ }^{31}$ Para los desafíos regulatorios que en Chile impone la transición a la televisión digital, ver Sierra (2006: 111-154). 


\section{ANEXO}

TABLA COMPARADA DE PRECIOS DE ACCESO A BA, CON DATOS DE 2003

\begin{tabular}{|c|c|c|c|c|}
\hline Economía & $\begin{array}{c}\text { Suscripción } \\
\text { mensual (USD) }\end{array}$ & $\begin{array}{c}\text { Precio por } 100 \\
\text { kbit/s (USD) }\end{array}$ & $\begin{array}{l}\text { Suscripción como } \\
\% \text { de ingreso } \\
\text { mensual }\end{array}$ & $\begin{array}{c}100 \mathrm{kbit} / \mathrm{s} \text { como } \\
\% \text { de ingreso } \\
\text { mensual }\end{array}$ \\
\hline Argentina & 22,44 & 8,77 & 3,71 & 1,45 \\
\hline Brasil & 71,19 & 27,81 & 3,89 & 1,52 \\
\hline Nueva Caledonia & 76,15 & 14,87 & 9,02 & 1,76 \\
\hline Polonia & 35,50 & 13,87 & 4,64 & 1,81 \\
\hline Chile & 106,10 & 41,44 & 8,01 & 3,13 \\
\hline Bahrein & 57,46 & 22,44 & 8,01 & 3,13 \\
\hline México & 75,31 & 29,42 & 10,11 & 3,95 \\
\hline Letonia & 80,00 & 31,25 & 11,62 & 4,54 \\
\hline Costa Rica & 99,00 & 19,34 & 24,75 & 4,83 \\
\hline Perú & 93,26 & 36,43 & 16,58 & 6,48 \\
\hline Granada & 238,65 & 93,22 & 24,65 & 9,63 \\
\hline Arabia Saudita & 174,75 & 68,26 & 31,39 & 12,26 \\
\hline Japón & 24,19 & 0,09 & 1,11 & $<0,01$ \\
\hline Corea (Rep. de) & 49,23 & 0,25 & 3,58 & 0,02 \\
\hline Bélgica & 34,41 & 1,15 & 1,51 & 0,05 \\
\hline Hong Kong, China & 38,21 & 1,27 & 1,71 & 0,06 \\
\hline Singapur & 33,18 & 2,21 & 1,69 & 0,11 \\
\hline Estados Unidos & 52,99 & 3,53 & 1,81 & 0,12 \\
\hline Canadá & 32,48 & 3,25 & 1,39 & 0,14 \\
\hline Holanda & 51,55 & 3,36 & 2,25 & 0,15 \\
\hline Macao, China & 38,34 & 2,56 & 2,43 & 0,16 \\
\hline Nueva Zelanda & 40,61 & 2,71 & 2,43 & 0,16 \\
\hline Alemania & 33,93 & 4,42 & 1,55 & 0,20 \\
\hline Noruega & 46,16 & 6,56 & 1,55 & 0,22 \\
\hline Israel & 20,40 & 3,98 & 1,27 & 0,25 \\
\hline Austria & 45,20 & 5,89 & 1,92 & 0,25 \\
\hline Eslovenia & 79,54 & 3,88 & 5,40 & 0,26 \\
\hline Italia & 73,59 & 6,13 & 3,49 & 0,29 \\
\hline Reino Unido & 32,59 & 6,37 & 1,51 & 0,30 \\
\hline Luxemburgo & 91,77 & 17,92 & 2,16 & 0,42 \\
\hline Suecia & 44,56 & 8,91 & 2,13 & 0,43 \\
\hline Suiza & 57,84 & 11,30 & 2,22 & 0,43 \\
\hline Australia & 50,56 & 9,87 & 2,25 & 0,44 \\
\hline Francia & 51,46 & 10,05 & 2,36 & 0,46 \\
\hline Irlanda & 61,69 & 12,05 & 2,64 & 0,52 \\
\hline Portugal & 39,64 & 7,74 & 2,74 & 0,54 \\
\hline Chipre & 58,03 & 9,07 & 3,86 & 0,60 \\
\hline Islandia & 73,66 & 14,39 & 3,09 & 0,60 \\
\hline Lituania & 12,80 & 5,00 & 1,55 & 0,61 \\
\hline Malta & 53,34 & 10,42 & 3,77 & 0,74 \\
\hline Jordania & 14,06 & 2,75 & 4,15 & 0,81 \\
\hline Dinamarca & 51,82 & 20,24 & 2,11 & 0,82 \\
\hline China & 30,10 & 7,84 & 3,70 & 0,96 \\
\hline Croacia & 24,26 & 9,48 & 2,62 & 1,02 \\
\hline Estonia & 49,72 & 4,86 & 10,58 & 1,03 \\
\hline Venezuela & 42,95 & 11,18 & 4,02 & 1,05 \\
\hline Hungría & 57,36 & 22,41 & 2,71 & 1,06 \\
\hline Finlandia & 47,63 & 18,61 & 2,79 & 1,09 \\
\hline España & 29,21 & 7,61 & 4,23 & 1,10 \\
\hline Malasia & 68,90 & 13,46 & 7,03 & 1,37 \\
\hline
\end{tabular}

Fuente: International Telecommunications Union, ITU, en http://www.itu.int/ osg/spu/spunews/2003/oct-dec/broadband.html. 


\section{BIBLIOGRAFÍA}

Benkler, Yochai (2006): The Wealth of Networks. New Haven: Yale University Press.

Breyer, Stephen (2004): Economic Reasoning and Judicial Review. Washington: AEI.

Centro de Estudios Públicos (CEP) (2007): "Estudio Nacional de Opinión Pública junio 2007”. Documento de Trabajo $N^{\circ}$ 369, agosto, disponible en http:// www.cepchile.cl.

Cisco (2007): “Barómetro Cisco de la Banda Ancha” (2007). En http://www.acti.cl/actualidad/noticias/barometro_18_01_2007.htm.

Corte Suprema (2007): Sentencia, recurso de reclamación Voissnet S.A. con Telefónica CTC Chile S.A., 04/07/2007. En http://www.poderjudicial.cl/index2.php?pagina1=causas/ esta402.php?h=AAANmYAAPAAA8jJAAR.

Donoso, Lorena (2002): “Servicio Universal de Telecomunicaciones”. En Revista Chilena de Derecho Informático, $\mathrm{N}^{\circ}$ 1, en http://www.derechoinformatico.uchile.cl/CDA/ der_informatico_complex/0,1491,SCID\%253D15360\%2526ISID\%253D291,00.html

Engel, Eduardo y Patricio Navia (2006): Que Gane 'El Más Mejor'. Mérito y Competencia en el Chile de Hoy. Santiago: Random House Mondadori, tercera edición.

González, Aldo y Andrés Gómez-Lobo (2006): “Desagregación en Internet de Banda Ancha en Chile”. Serie Documentos de Trabajo, No 226, FACEA, Santiago.

Lessig, Lawrence (s/f): “Cultura Libre. Cómo los Grandes Medios Están Usando la Tecnología y las Leyes para Encerrar la Cultura y Controlar la Creatividad”. En http://www.cedi.uchile.cl/docs/Culturalibre.pdf.

Ministerio de Economía (2007): "Plan Estratégico de Desarrollo Digital 2007-2010”. Comité de Ministros para el Desarrollo Digital. En http://www.economia.cl/aws00/ Estatico/repositorio/c/R/X/ipVZIukVgIbyybk_Qx6S6YrA=.pdf.

Neuchterlein, Jonathan E. y Philip J. Weiser (2005): Digital Crossroads. American Telecommunications Policy in the Internet Age. Cambridge, Mass.: MIT.

Sierra, Lucas (2006): “Hacia la TV Digital en Chile: Historia y Transición”. En Estudios Públicos, $\mathrm{N}^{\circ} 103$, invierno.

Subtel (2004a): Documento de Consulta, "Marco de Referencia Reglamento para Servicios de Desagregación de Redes”. En http:/www.subtel.cl/pls/portal30/docs/FOLDER/ WSUBTEL_CONTENIDOS_SITIO/SUBTEL/CONSULTA_PUBLICA/CONSULTA/ MARCO_REFERENCIA_SSDR/MARCO_REFERENCIA_REGLAMENTO_SSDR.PDF.

Subtel (2004b): Documento de Consulta, "Regulación de los Servicios de VoIP” (Agenda Digital). Julio. En http://www.subtel.cl/pls/portal30/docs/FOLDER/WSUBTEL_ CONTENIDOS_SITIO/SUBTEL/CONSULTA_PUBLICA/CONSULTA/ DOC_CONSULTA_PUB_VOIP/DOCUMENTO_DE_CONSULTA_VOIP.PDF. Sus reacciones están en http://www.subtel.cl/servlet page?_pageid=58\&_dad=portal30\&_ schema=PORTAL30.

Subtel (2006): Documento de Consulta, "Reglamento de Servicio Público de Voz sobre Internet”. En http://www.subtel.cl/prontus_subtel/site/artic/20070413/asocfile/ 20070413171803/consulta_publica_voip_201206.pdf.

Subtel (2007a): "Estadísticas e Indicadores por Tipo de Servicio. Abonados Móviles”. Disponible en http://www.subtel.cl/prontus_subtel/site/artic/20070212/ pags/20070212182348.html\#T1.

Subtel (2007b): "Estadísticas e Indicadores por Tipo de Servicio. Serie Líneas Telefónicas”. Disponible en http://www.subtel.cl/prontus_subtel/site/artic/ 20070212/pags/20070212182348.html\#T1. 
Subtel (2007c): “Indicadores de Penetración de Internet”. En http://www.subtel.cl/ prontus_subtel/site/artic/20070212/asocfile/20070212182348/2_indicadores_ penetracion_internet.XLS.

The Economist (2001): “The Shape of Phones to Come”. En The Economist, March 22. Disponible en http://www.economist.com/displaystory.cfm?story_id=E1_VPJSTS.

The Economist (2007a): "Drop the Computer". En The Economist, January $11^{\text {th }}$. Disponible en http://www.economist.com/business/displaystory.cfm?story_id=8521960.

The Economist (Technology Quarterly) (2007b): "Watching the Web Grow Up". The Economist (Technology Quarterly), March 8 ${ }^{\text {th }}$. Disponible en http://www. economist.com/search/displaystory.cfm?story_id=8766093.

Tribunal de Defensa de la Libre Competencia (TDLC) (2004): Resolución, consulta VTRMetrópolis, 24/10/2004. En http://www.tdlc.cl/db_images/resoluciones/ 42d6afeed6a87_Resolucion-1-2004.pdf.

Tribunal de Defensa de la Libre Competencia (TDLC) (2006): Sentencia, caso Voissnet S.A. con Telefónica CTC Chile S.A., 26/10/2006. En http://www.tdlc.cl/db_images/sentencias/45411f978d854_Sentencia-45-2006.pdf. 
